\title{
Risk-premia, Carry-trade Dynamics, and Economic Value of Currency Speculation
}

Wagner, Christian

\author{
Document Version \\ Final published version \\ Published in: \\ Journal of International Money and Finance
}

DOI:

10.1016/j.jimonfin.2012.01.013

Publication date:

2012

License

CC BY-NC-ND

Citation for published version (APA):

Wagner, C. (2012). Risk-premia, Carry-trade Dynamics, and Economic Value of Currency Speculation. Journal of International Money and Finance, 31(5), 1195-1219. https://doi.org/10.1016/j.jimonfin.2012.01.013

Link to publication in CBS Research Portal

\section{General rights}

Copyright and moral rights for the publications made accessible in the public portal are retained by the authors and/or other copyright owners and it is a condition of accessing publications that users recognise and abide by the legal requirements associated with these rights.

\section{Take down policy}

If you believe that this document breaches copyright please contact us (research.lib@cbs.dk) providing details, and we will remove access to the work immediately and investigate your claim.

Download date: 26. Apr. 2023 
NOTICE: this is the author's version of a work that was accepted for publication in Journal of International Money and Finance. Changes resulting from the publishing process, such as peer review, editing, corrections, structural formatting, and other quality control mechanisms may not be reflected in this document. Changes may have been made to this work since it was submitted for publication. A definitive version was subsequently published in Journal of International Money and Finance, Vol31, Issue5, September 2012. DOI:10.1016/j.jimonfin.2012.01.013

\title{
Risk-Premia, Carry-Trade Dynamics, and Economic Value of Currency Speculation*
}

\author{
Christian Wagner \\ Vienna University of Economics and Business ${ }^{\dagger}$
}

\begin{abstract}
In this paper, we derive the dynamics and assess the economic value of currency speculation by formalizing the concept of a trader inaction range. We show that exchange rate returns comprise a time-varying risk-premium and that uncovered interest parity (UIP) holds in a speculative sense. The often-cited 'forward bias puzzle' originates from the omission of the risk-premium in standard UIP tests. Consistent with its popularity among market professionals, the carry-trade strategy can be rationalized as it systematically collects risk-premia and generates economic value when applied in multi-currency portfolios.
\end{abstract}

JEL classification: F31;

Keywords: Exchange rates; Uncovered interest parity; Risk-premia; Carry-trade; Economic value.

\footnotetext{
${ }^{*}$ The author is indebted for useful conversations or constructive comments to Geert Bekaert, Chris D'Souza, Alois Geyer, Frank Heinemann, Lucio Sarno, Maik Schmeling, and Josef Zechner as well as participants at the meetings of the European Finance Association, 2008; German Finance Association, 2008; and seminars at the Vienna University of Economics and Business and the Austrian Central Bank.

${ }^{\dagger}$ Postal address: Department of Finance, Heilligenstaedterstrasse 46-48, A-1190 Vienna, Austria. Phone: +43-131336-4253. Fax: +43-1-31336-736. E-mail: christian.wagner@wu.ac.at.
} 


\section{Introduction}

Tests of foreign exchange market efficiency are typically based on an assessment of uncovered interest rate parity (UIP). UIP postulates that the expected change in a bilateral exchange rate is equal to the forward premium, i.e., given that covered interest rate parity holds, it compensates for the interest rate differential. However, starting with the seminal work by Hansen and Hodrick (1980), Bilson (1981), and Fama (1984), empirical research provides evidence that the forward rate is a biased estimate of the future spot rate, finding that the higher interest rate currency tends to not depreciate as much as predicted by UIP or even appreciates. A consequence of the empirical failure of UIP is that foreign exchange excess returns appear to be predictable, i.e. the lagged forward premium has explanatory power for subsequent excess returns. Attempts to explain this 'forward bias puzzle' using, among others, risk-premia, consumption-based asset pricing theories, and term-structure models have met with limited success.

While exchange rate anomalies are usually considered to be macro puzzles, the results of recent research suggest to take a look under the microstructure lamppost. Evans and Lyons (2002) argue that order-flow conveys information that is relevant to the determination of exchange rates and present empirical evidence strongly supporting their point. The finding that order-flow drives exchange rates suggests that scrutinizing the trading behavior of market participants who generate order-flow may offer deeper insight into the nature of exchange rate puzzles. Lyons (2001) builds on that idea and argues that the forward bias and the predictability of excess returns might be statistically significant but nevertheless unimportant in economic terms due to limits to speculation: compared to other investment opportunities, the Sharpe ratios realizable from currency speculation are too small to attract traders' capital. This presumption that traders allocate capital only if Sharpe ratios exceed a certain threshold implies a range of trader inaction for smaller UIP deviations. Within this range, traders do not produce order-flow aimed at exploiting the forward bias which, as a consequence, remains persistent. Empirical research suggests that bilateral exchange rates are characterized by a statistically persistent but economically small forward bias, see Sarno et al. (2006), thus being in line with the general idea of limits to speculation. However, Della Corte et al. (2008) show that dynamic multi-currency strategies yield large economic gains which is consistent with the widespread use of forward bias strategies among market professionals.

The present paper formalizes the Lyons (2001) concept of the trader inaction range as a device to assess the economic value of currency speculation. For this purpose, we take a two-step approach. First, we formulate speculative pendants to the standard UIP test to examine whether currency speculation yields non-zero profits. Second, we judge the economic significance of resulting Sharpe ratios via trader inaction ranges implied by limits to speculation. The exchange rate dynamics implied by speculative UIP suggest that exchange rate changes indeed just follow the forward premium but additionally comprise a time-varying risk component which depends on the deviation of the current forward premium from its long-run mean. We show that the forward bias puzzle reported in previous research stems from omitting this risk-premium in standard UIP tests. Furthermore, the use of carrytrades aimed at exploiting the forward bias can be rationalized in the presence of such a risk-premium, 
which is consistent with the carry-trade's huge popularity among market participants. We also show that an assessment of economic value within the Fama-regression framework necessitates to take a close look at the regression constant. While research assessing the statistical significance of UIP deviations heavily focuses on the Fama-regression slope coefficient, disregarding the intercept leads to overestimating currency excess returns and consequently to spurious conclusions with respect to economic value.

Empirically, we find support for speculative UIP and the existence of a risk-premium, the omission of which results in the forward bias puzzle. Carry-traders are able to collect risk-premia and to generate positive excess returns. Whereas the economic value of these excess returns is limited for bilateral carrytrades, we provide evidence that portfolio strategies involving multiple currencies indeed generate economic value. Furthermore, the results of our empirical analysis also support our emphasis to explicitly account for the regression intercept when judging the economic value of currency speculation.

Our paper is thus closely related to Della Corte et al. (2008) who also find that multi-currency strategies generate economic value. While their focus rests more on the design of the dynamic asset allocation strategy, our work goes beyond their analysis in that we show (i) that exchange rate returns comprise a time-varying risk-premium, (ii) how carry-traders are able to collect this risk-premium, thereby providing a direct rationale for the strategy, and (iii) that the forward bias puzzle originates from the omission of the risk-premium in standard UIP tests. Furthermore, a particularly nice feature of our framework is that it can be directly applied to the standard Fama-regression setup. Hence, it equips the large research community working on related studies with an effective testing procedure which is straight-forward in its implementation and provides material information about the economic relevance of UIP deviations. Moreover, we discuss various directions in which one can extend the analysis of our paper in future research.

The remainder of this paper is organized as follows. We briefly review the related literature in section 2 and provide a short outline of our framework in section 3. In section 4 we derive the speculative pendants to the standard UIP test and describe the exchange rate dynamics implied by speculative UIP. We derive trader inaction ranges to judge economic value in section 5. Empirical results, their implications, and extensions for future research are presented in section 6 . Section 7 offers a conclusion. All tables and figures are gathered at the end of the paper. The separate appendix is organized as follows: Appendix A. generalizes the derivation of section 4 by additionally allowing for an unconditional (country) risk-premium. Appendix B. provides technical details with respect to the derivation of trader inaction ranges, Appendix C. describes the procedure for testing whether inaction range bounds are over- or undershot.

\section{Related Literature on UIP and Currency Speculation}

Uncovered interest parity (UIP) postulates that the expected exchange rate change compensates for the interest rate differential prevailing for the respective countries. Given that covered interest parity holds, the interest rate differential equals the forward premium. A standard test of UIP is the Fama 
(1984) regression,

$$
\Delta s_{t+1}=\alpha+\beta p_{t}^{1}+\varepsilon_{t+1}
$$

where $s_{t}$ denotes the logarithm of the spot exchange rate (domestic price of foreign currency) at time $t, p_{t}^{1}$ the one-period forward premium, i.e. $f_{t}^{1}-s_{t}$ with $f_{t}^{1}$ being the logarithm of the one-period forward rate, and $\Delta$ a one-period change. The null hypothesis that UIP holds is represented by $\alpha$ being zero and $\beta$ equalling unity. The common finding that empirical research over the last decades provided and concentrated on is that $\beta$ is typically lower than unity and often negative. This indicates that the higher interest rate currency tends to not depreciate as much as predicted by UIP or even appreciates, apparently allowing for predictable excess returns over UIP. Seminal articles in this area are Hansen and Hodrick (1980), Bilson (1981), and Fama (1984), surveys of the literature include Hodrick (1987), Froot and Thaler (1990), Taylor (1995), Lewis (1995), Engel (1996), Sarno (2005).

Fama (1984) argues that the forward bias may be caused by a time-varying risk-premium that is more volatile than, and negatively correlated with, the expected rate of currency depreciation. However, traditional risk-based explanations have in general had limited success in explaining the observed linkages between exchange rates and interest rates; see e.g. Bekaert and Hodrick (1993) and Bekaert and Hodrick (2001). In particular, attempts to explain the forward bias puzzle using models of risk-premia suggest that unrealistically high degrees of risk aversion must be assumed to match the two Fama (1984) conditions; see e.g. Frankel and Engel (1984); Domowitz and Hakkio (1985); Cumby (1988); Mark (1988); Engel (1996); Lustig and Verdelhan (2007). Moreover, it is difficult to explain the rejection of UIP and the forward bias puzzle by recourse to traditional consumption-based asset pricing theories which allow for departures from time-additive preferences (Backus et al., 1993; Bansal et al., 1995; Bekaert, 1996) and from expected utility (Bekaert et al., 1997), or by using popular models of the term structure of interest rates adapted to a multi-currency setting (Bansal, 1997; Backus et al., 2001; Brennan and Xia, 2006). More recently, Verdelhan (2008) offers an explanation to the puzzle based on a model in which investors have preferences with external habits. Brunnermeier et al. (2008), Farhi and Gabaix (2008), and Jurek (2008) argue that currency (excess) returns comprise a premium for crash risk.

While exchange rate anomalies are usually considered to be macro puzzles, the results of recent research suggest to take a look under the microstructure lamppost. Evans and Lyons (2002) argue that order-flow conveys information that is relevant to the determination of exchange rates and present empirical evidence strongly supporting their point. ${ }^{1}$ The finding that order-flow drives exchange rates suggests that scrutinizing the trading behavior of market participants who generate order-flow may offer deeper insight into the nature of exchange rate puzzles. Lyons (2001) builds on that idea and suggests a microstructural approach building on institutional realities: Traders only allocate capital to currency speculation if they expect a higher Sharpe ratio than from other investment opportunities, i.e. some threshold in terms of the Sharpe ratio has to be exceeded. ${ }^{2}$ Lyons (2001) argues that returns

\footnotetext{
${ }^{1}$ Other papers emphasizing the role of order-flow in foreigen exchange markets include, among others, Lyons (1995), Ito et al. (1998), Rime (2001), Lyons (2002), Evans and Lyons (2004), Bjønnes and Rime (2005), Dominguez and Panthaki (2006), Evans and Lyons (2006), Taylor and Sager (2008), Rime et al. (2008).

${ }^{2}$ Lyons (2001) stresses that speculative capital is allocated based on Sharpe ratios in practice. This empirical reality is important for his concept rather than a theoretical rational for why such a behavior arises.
} 
from currency speculation depend on how far $\beta$ deviates from unity. For minor UIP deviations, Sharpe ratios are too small to attract speculative capital, thereby implying a range of trader inaction in the vicinity of UIP. Lyons (2001) states that $\beta$ s around -1 or 3 are necessary to achieve a Sharpe ratio of 0.4 , the long run performance of a buy-and-hold strategy in US equities. Accordingly, he suggests that a range of $\beta$-values between approximately -1 and 3 characterizes a trader inaction band, within which $\beta$ might be statistically different from unity but without economic relevance.

Inspired by the concept of limits to speculation, Sarno et al. (2006) investigate the relationship between spot and forward rates in a smooth transition regression framework. They report evidence for such a non-linear relationship, allowing for a time-varying forward bias. The empirical results indicate that UIP does not hold most of the time but (expected) deviations from UIP are economically insignificant, i.e. too small to attract speculative capital. Burnside et al. (2006) argue that transaction costs and price pressure limit the extent to which traders try to exploit the anomaly. Real world market evidence, however, suggests that the carry-trade strategy aimed at exploiting the forward bias is highly popular among financial institutions and extensively used in practice. For instance, Galati and Melvin (2004) and Galati et al. (2007) argue that the use of carry-trades is a key driver for the surge of foreign exchange trading activity in recent years. Villanueva (2007) provides evidence that the forward premium allows for directional predictability which translates into statistically significant profits from trading on the forward bias. Della Corte et al. (2008) find that conditioning on the forward premium produces economic value in multi-currency portfolios. In particular, they show that a riskaverse investor will pay a high performance fee to switch from a dynamic portfolio strategy based on the random walk model to one that conditions on the forward premium. Related, Burnside et al. (2008) show that diversifying the carry-trade across currencies boosts Sharpe ratios by over $50 \%$. Hochradl and Wagner (2008) argue that carry-trade portfolios have the potential to attract speculative capital as they outperform benchmark stock- and bond-index investments. In this paper, we formalize the concept of the trader inaction range, which allows us to derive the dynamics of currency speculation, to analyze their linkage to risk-premia, and to assess the economic value attainable.

\section{Outline of the Framework}

Instead of investigating the efficiency of currency markets by standard UIP tests, we assess the economic value of currency speculation. ${ }^{3}$ We build on Lyons (2001) who argues that deviations of the Famaregression $\beta$ form its UIP-theoretic value may not be important in economic terms as long as deviations are too small to attract speculative capital. We extend his logic to the regression constant $\alpha$ and argue that for UIP in a speculative sense $\alpha$ and $\beta$ do not always have to correspond to their standardly hypothesized values but rather that deviations of one or both might occur as long as these do not allow for economically significant profits.

By economic significance we mean that finding excess returns to be statistically different from zero, is not sufficient in economic terms. Profits can be strictly positive but still too small to attract

\footnotetext{
${ }^{3}$ While we are quite general in our nomenclature, we will particularly focus on trading strategies on the basis of interest rate differential information.
} 
capital. Traders compare currency speculation approaches to other investment opportunities, e.g. a buy-and-hold equity investment, and speculative capital would only be allocated to currency strategies offering a higher Sharpe ratio than other investments. Otherwise, no capital would be allocated, thus no order flow produced, and hence the bias be left unexploited and persistent, being visible statistically but without economic relevance.

We therefore take a two-step approach to assess the economic value of currency speculation. First, we formulate speculative pendants to the standard UIP test, to examine whether currency speculation yields non-zero profits. If profits are statistically different from zero, we judge the economic significance of resulting Sharpe ratios via trader inaction ranges implied by limits to speculation. We provide a formalization of the idea verbally described by Lyons (2001) which also goes beyond the analysis of Sarno et al. (2006), as we derive trader inaction ranges analytically. This does not only allow us to empirically test the predictions of the limits to speculation hypothesis that currency speculation should not generate economic value, but also to analyze the dynamics of currency speculation and their linkage to risk-premia.

\section{Speculative UIP, Risk-Premia, and Dynamics of Speculation}

Starting from a static trading approach, i.e. a permanent long (or short) position in the foreign currency, which can be viewed as a lower benchmark for speculative efficiency, we motivate a speculative UIP test on the Fama-regression. Speculative UIP implies that exchange rate dynamics comprise a time-varying risk-premium and we show that its omission in standard UIP tests causes the forward bias puzzle. We propose a test for this risk-premium and outline the dynamics of excess returns from the static trading approach as well as the carry-trade.

\subsection{Static Trading Approach: Risk-Premia and Excess Return Dynamics}

Building on the argument of Lyons (2001) that traders use Sharpe ratios to evaluate the performance of their trading strategies, it is instructive to reparametrize the regression in equation (1) in terms of excess returns. We use the standard definition of excess returns given by the difference between the exchange rate return and the lagged premium, see e.g. Bilson (1981), Fama (1984), and Backus et al. (1993), Sarno et al. (2006), $E R_{t+1} \equiv \Delta s_{t+1}-p_{t}^{1} \equiv s_{t+1}-f_{t}^{1}$, yields

$$
E R_{t+1}=\alpha+(\beta-1) p_{t}^{1}+\varepsilon_{t+1},
$$

where $E R_{t+1}$ corresponds to the payoff of a long forward position in the foreign currency entered at time $t$ and maturing at $t+1$. Analogously, $-E R_{t+1}$ corresponds to a short position. ${ }^{4}$ Market efficiency arguments suggest that in the long-run excess returns should be zero on average. Given that the domestic and the foreign interest rates are stationary, the forward premium reverts to a long-run

\footnotetext{
${ }^{4}$ Equivalently, one could enter corresponding spot market and money market transactions.
} 
mean which we denote by $\mu_{p} .{ }^{5}$ The long-run average of excess returns, $\overline{E R}$, can then be written as

$$
\overline{E R}=\alpha+(\beta-1) \mu_{p}
$$

Note that, since the Fama-regression is usually estimated by OLS, by the least squares principle the average residual is zero because the regression includes a constant. The standard procedure to assess whether UIP holds is to test the restrictions $\alpha=0$ and $\beta=1$ which implies that $\overline{E R}=0$. If one relaxes the assumption of risk-neutrality, the average excess return should reflect an unconditional riskpremium depending on the riskiness of the foreign currency held. The sign of the premium depends on whether holding the foreign currency as compared to the domestic currency is associated with more risk (e.g. political risk, transition effects) or less (e.g. foreign country is a "safe haven"). For the ease of presentation, we discuss the case where the unconditional risk-premium is zero below, analogous derivations for a non-zero country risk-premium are provided in Appendix A..

Given that holding the currencies of the two countries is equally risky, the average excess return should be zero. Taking a speculative efficiency perspective, one notes that an average excess return of zero does not only result if $\alpha$ and $\beta$ exactly correspond to these theoretical values but for any values that satisfy the less restrictive relationship $\alpha=-(\beta-1) \mu_{p}$. Hence, both parameters might deviate from their hypothesized values but still not allow for a non-zero average excess return. In fact, this illustrates that if one of the parameters deviates from its theoretical value, the other one should do so as well such that the average excess return growing with the deviation of the one parameter is reduced by an opposing deviation of the other one. In our empirical analysis we formally test for the existence of such offsetting effects which is equivalent to testing whether average profits from the static trading approach are zero. Since previous research usually reports tests on whether $\beta=1$, we formulate our test in terms of $\beta$ as well, proposing

Test 1 (Speculative UIP Test): For the parameters of the Fama-regression (1), we test the hypothesis $\beta=1-\alpha / \mu_{p}$. If this restriction holds, offsetting effects between $\alpha$ and $\beta$ exist and average excess returns from the static trading approach are zero.

For the subsequent derivation we conjecture that the relationship $\beta=1-\alpha / \mu_{p}$ holds, i.e. we conjecture a minimum level of speculative efficiency. Otherwise, non-zero excess returns could be generated in the long-run - even though the unconditional country risk-premium is zero - just by taking a permanent long or short position in the foreign currency. Imposing the restriction on the Fama-regression (1) yields

$$
\Delta s_{t+1}=\alpha-\alpha \frac{p_{t}^{1}}{\mu_{p}}+p_{t}^{1}+\varepsilon_{t+1}
$$

and rewriting the excess return equation (2) gives

$$
E R_{t+1}=\alpha-\alpha \frac{p_{t}^{1}}{\mu_{p}}+\varepsilon_{t+1}
$$

\footnotetext{
${ }^{5}$ We consciously leave interest rate modeling outside the scope of this paper. For the purpose of motivating our arguments it is sufficient to build on the theoretical and empirical results of previous work that interest rates are mean reverting. We take up this issue again in section 6.3 where we discuss potential extensions to our framework.
} 
The spot rate dynamics as given in (4) can be described as follows: the core movement in the change of the exchange rate corresponds just to the forward premium, $p_{t}^{1}$, as postulated by UIP. Additionally, $\Delta s_{t+1}$ is driven by a constant term, $\alpha$, and a component, $-\alpha \frac{p_{t}^{1}}{\mu_{p}}$, that is governed by the extent to which the forward premium at $t$ deviates from its long-run mean. Hence, our dynamics suggest that temporary deviations from UIP are possible, but in the long-run reversion towards the parity condition occurs. Note that this specification is consistent with other exchange rate modeling approaches established in the literature such as regime switching models, e.g. Engel and Hamilton (1990), vector error correction models, see e.g. Brenner and Kroner (1995), Zivot (2000), and Clarida et al. (2003), and smooth transition regression frameworks recently applied by e.g. Sarno et al. (2006). In this context, $\alpha$ plays a role in determining the reversion to long-run UIP. Defining $\bar{\alpha}=\alpha / \mu_{p}$ we can rewrite equations (4) and (5) as

$$
\begin{aligned}
\Delta s_{t+1} & =\bar{\alpha}\left(\mu_{p}-p_{t}^{1}\right)+p_{t}^{1}+\varepsilon_{t+1}, \\
E R_{t+1} & =\bar{\alpha}\left(\mu_{p}-p_{t}^{1}\right)+\varepsilon_{t+1}
\end{aligned}
$$

where $\bar{\alpha}$ should be positive, i.e. $\alpha$ should have the same sign as $\mu_{p}$, to ensure expedient convergence to long-run UIP. This, however, suggests that over shorter horizons deviations from UIP occur and that excess returns represent a time-varying risk-premium.

Given that the exchange rate process is indeed governed as represented in (4), estimating the Fama-regression (1) leads to a biased estimate of $\beta$ due to the omission of $-\alpha \frac{p_{t}^{1}}{\mu_{p}}$ :

$$
\mathrm{E}[\beta]=\beta^{U I P}-\alpha\left\{\frac{\operatorname{cov}\left[p_{t}^{1} ; p_{t}^{1} / \mu_{p}\right]}{\sigma_{p}^{2}}\right\}=1-\alpha\left\{\frac{1}{\mu_{p}}\right\} .
$$

As argued above for equation (6), $\alpha$ and $\mu_{p}$ should have the same sign to ensure a proper reversion towards long-run UIP. This suggests that the slope coefficient in the Fama-regression will be biased downwards from its theoretical UIP value, $\beta^{U I P}=1$, which is consistent with empirical research documenting the forward bias puzzle. Hence, our results contribute to the literature attempting to explain the puzzle by recourse to risk-premium arguments, for a survey see e.g. Engel (1996), and are in line with research suggesting that standard UIP tests may be non-informative in the presence of an omitted risk-premium, see e.g. Barnhart et al. (1999). Our empirical analysis is based on equation (5) for which we present unrestricted estimates as given by

$$
E R_{t+1}=\alpha_{1}+\alpha_{2} \frac{p_{t}^{1}}{\mu_{p}}+\varepsilon_{t+1}
$$

The attempt to explain the forward bias puzzle by recourse to risk-premium arguments is supported if $\alpha_{2}$ is significantly different from zero and if one cannot reject that $\alpha_{1}=-\alpha_{2}$. Note that the latter is ensured if one finds evidence for offsetting effects between $\alpha$ and $\beta$ (Test 1); finding $\alpha_{1} \neq-\alpha_{2}$ would be indicative for the presence of a non-zero country risk-premium, see Appendix A.. Accordingly, we formulate

Test 2 (RIsk-PREmium TeSt): For the parameters of regression (8), we test the hypotheses 
$\alpha_{2}=0$ and $\alpha_{1}=-\alpha_{2}$. If the former restriction is rejected and the latter holds, a non-zero riskpremium exists.

If a non-zero risk-premium exits, the (long-run) dynamics of excess returns from the static trading approach can be described by enumerating all possible scenarios. Although we provided a rationale above that we expect $\beta<1$ in the long-run, we also present scenarios where $\beta>1$ since we refer to these scenarios in the next subsection. Overall, the excess return process can be summarized in 12 scenarios which depend on the sign of $\mu_{p}$, the relation between $p_{t}^{1}$ and $\mu_{p}$ and the combination of $\beta$ and $\alpha$ values:

\begin{tabular}{|c|c|c|c|}
\hline \multicolumn{4}{|c|}{$\mu_{p}>0$} \\
\hline & $\beta<1, \alpha>0$ & $\beta>1, \alpha<0$ & \\
\hline $0<\mu_{p}<p_{t}^{1}$ & $E R_{t+1}<0$ & $E R_{t+1}>0$ & {$[1 \mathrm{a}, 1 \mathrm{~b}]$} \\
\hline $0<p_{t}^{1}<\mu_{p}$ & $E R_{t+1}>0$ & $E R_{t+1}<0$ & {$[2 \mathrm{a}, 2 \mathrm{~b}]$} \\
\hline$p_{t}^{1}<0<\mu_{p}$ & $E R_{t+1}>0$ & $E R_{t+1}<0$ & {$[3 \mathrm{a}, 3 \mathrm{~b}]$} \\
\hline \multicolumn{4}{|c|}{$\mu_{p}<0$} \\
\hline & $\beta<1, \alpha<0$ & $\beta>1, \alpha>0$ & \\
\hline$\mu_{p}<0<p_{t}^{1}$ & $E R_{t+1}<0$ & $E R_{t+1}>0$ & {$[4 \mathrm{a}, 4 \mathrm{~b}]$} \\
\hline$\mu_{p}<p_{t}^{1}<0$ & $E R_{t+1}<0$ & $E R_{t+1}>0$ & {$[5 \mathrm{a}, 5 \mathrm{~b}]$} \\
\hline$p_{t}^{1}<\mu_{p}<0$ & $E R_{t+1}>0$ & $E R_{t+1}<0$ & {$[6 \mathrm{a}, 6 \mathrm{~b}]$} \\
\hline
\end{tabular}

A "perfect" speculation strategy would take long and short positions such as to always realize positive excess returns, which requires perfect knowledge or foresight of the long-run forward premium $\mu_{p}$. This is consistent with the literature showing that the term-structure of forward premia, contains useful information for predicting exchange rates; see e.g. Clarida and Taylor (1997), Clarida et al. (2003), and Boudoukh et al. (2006). In practice, market participants often use simpler trading rules like the carry-trade described in the next subsection.

\subsection{Exploiting the Forward Bias: Carry-Trade}

The empirical evidence that the Fama- $\beta$ is typically negative has of course also been recognized by practicioners and motivated the design of trading rules attempting to exploit the forward bias; see e.g. Deutsche Bank (2004). Carry-trade strategies - take a long position in the higher interest rate currency, financed by a short position in the low interest rate currency - are highly popular among market participants; see e.g. Galati and Melvin (2004), Galati et al. (2007).

The excess return from a bilateral carry-trade can be written in terms of $E R_{t+1}$ introduced in (2): one would sell forward the foreign currency at time $t$ if $p_{t}^{1}>0$ and realize a payoff of $-E R_{t+1}$ at $t+1$; a long position is entered if $p_{t}^{1}<0$, yielding a payoff of $E R_{t+1}$ :

$$
C T_{t+1}= \begin{cases}E R_{t+1}=\alpha+(\beta-1) p_{t}^{1}+\varepsilon_{t+1} & \text { if } p_{t}^{1}<0 \\ -E R_{t+1}=-\alpha-(\beta-1) p_{t}^{1}-\varepsilon_{t+1} & \text { if } p_{t}^{1}>0\end{cases}
$$

It is instructive to reconcile this representation of carry-trade profits with the excess return dynamics of the static trading approach outlined in the previous section by summarizing the dynamics of carrytrade profits: 


\begin{tabular}{|c|c|c|c|}
\hline \multicolumn{4}{|c|}{$\mu_{p}>0$} \\
\hline & $\beta<1, \alpha>0$ & $\beta>1, \alpha<0$ & \\
\hline $0<\mu_{p}<p_{t}^{1}$ & $E R_{t+1}<0 \quad C T_{t+1}>0$ & $E R_{t+1}>0 \quad C T_{t+1}<0$ & {$[1 \mathrm{a}, 1 \mathrm{~b}]$} \\
\hline $0<p_{t}^{1}<\mu_{p}$ & $E R_{t+1}>0 \quad C T_{t+1}<0$ & $E R_{t+1}<0 \quad C T_{t+1}>0$ & {$[2 \mathrm{a}, 2 \mathrm{~b}]$} \\
\hline$p_{t}^{1}<0<\mu_{p}$ & $E R_{t+1}>0 \quad C T_{t+1}>0$ & $E R_{t+1}<0 \quad C T_{t+1}<0$ & {$[3 \mathrm{a}, 3 \mathrm{~b}]$} \\
\hline \multicolumn{4}{|c|}{$\mu_{p}<0$} \\
\hline & $\beta<1, \alpha<0$ & $\beta>1, \alpha>0$ & \\
\hline$\mu_{p}<0<p_{t}^{1}$ & $E R_{t+1}<0 \quad C T_{t+1}>0$ & $E R_{t+1}>0 \quad C T_{t+1}<0$ & {$[4 \mathrm{a}, 4 \mathrm{~b}]$} \\
\hline$\mu_{p}<p_{t}^{1}<0$ & $E R_{t+1}<0 \quad C T_{t+1}<0$ & $E R_{t+1}>0 \quad C T_{t+1}>0$ & {$[5 \mathrm{a}, 5 \mathrm{~b}]$} \\
\hline$p_{t}^{1}<\mu_{p}<0$ & $E R_{t+1}>0 \quad C T_{t+1}>0$ & $E R_{t+1}<0 \quad C T_{t+1}<0$ & {$[6 \mathrm{a}, 6 \mathrm{~b}]$} \\
\hline
\end{tabular}

Although carry-trades are motivated by the intention to profit from $\beta$ less than unity, positive excess returns only emerge in four out of six scenarios where $\beta<1$. While a loss is incurred in scenarios $2 \mathrm{a}$ and $5 \mathrm{a}$ although $\beta<1$, carry-trades are profitable in scenarios $2 \mathrm{~b}$ and $5 \mathrm{~b}$ even though $\beta>1$. We discuss the pitfalls of exclusively focusing on $\beta$ and neglecting offsetting effects of $\alpha$ in section 4.3. Nevertheless, since we argued in the previous subsection that $\beta$ should be less than unity, the use of carry-trade strategies can be rationalized as it successfully captures risk-premia in most scenarios. In particular, it can be viewed as a proxy to the prefect foresight strategy as it conditions on $p_{t}^{1}$ but not on $\mu_{p}$.

In order to formulate a test of zero-profitability of carry-trades we rewrite equation (10). Since the sign of the position taken in the foreign currency is opposite to the sign of the forward premium, i.e. long if $p_{t}^{1}<0$ respectively short if $p_{t}^{1}>0$, we adjust the parameters and residuals of the Famaregression accordingly. To indicate that a component $i$ of the regression is adjusted for the position taken, we use superscript ', with $i^{\prime}=-\operatorname{sgn}\left[p_{t}^{1}\right] i$. Hence, the excess return from the carry-trade can be written as

$$
\begin{aligned}
& C T_{t+1}=E R_{t+1}^{\prime}=\alpha^{\prime}+(\beta-1)\left(p_{t}^{1}\right)^{\prime}+\varepsilon_{t+1}^{\prime}, \\
& \overline{C T}=\overline{\alpha^{\prime}}+(\beta-1) \overline{p^{\prime}}+\overline{\varepsilon^{\prime}} .
\end{aligned}
$$

Note that, if over the investigated period the sign of the premium changes at least once, $\alpha^{\prime}$ is not a constant and the mean of $\varepsilon_{t+1}^{\prime}$ is non-zero. Therefore, the means of $\alpha^{\prime},\left(p_{t}^{1}\right)^{\prime}$, and $\varepsilon_{t+1}^{\prime}$ are components of the average carry-trade excess return $\overline{C T}$. Excess returns from the carry-trade are not significantly different from zero if the restriction $\beta=1-\left(\overline{\alpha^{\prime}}+\overline{\varepsilon^{\prime}}\right) / \overline{p^{\prime}}$ holds on the parameters in regression (1).

Test 3 (Carry-Trade Zero Profit Test): For the parameters of the Fama-regression (1), we test the hypothesis $\beta=1-\left(\overline{\alpha^{\prime}}+\overline{\varepsilon^{\prime}}\right) / \overline{p^{\prime}}$. If this restriction holds, average excess returns from the carry-trade are zero.

In the derivation of the trader inaction ranges to judge the economic value of carry-trade speculation as well as in our empirical analysis, we also consider carry-trade portfolios. 


\subsection{The Pitfalls of Exclusively Focusing on $\beta$}

The Fama-regression (1) assesses market efficiency as a joint test of rational expectations and riskneutrality. While rational expectations imply that $\beta=1$ and that the forecast error $\left(\varepsilon_{t+1}\right)$ is uncorrelated with information at $t$, risk-neutrality suggests that $\alpha=0$. A non-zero $\alpha$ would represent a constant risk-premium. Hundreds of studies have estimated the Fama-regression for different exchange rates and sample periods with the focus of discussion always directed towards $\beta$. Hodrick (1992) cautioned that interpreting the negative $\beta$ as evidence that the forward premium mispredicts the direction of subsequent exchange rate returns may be misleading because authors ignore the constant even though it is relatively large. Similarly, Bekaert and Hodrick (2009) point out in their textbook (Chapter 7, p. 239) that people familiar with the regression result of a negative slope coefficient

"[...] argue that investors should do the "carry-trade" - that is, borrow in the foreign currency to earn both the higher yield and the expected capital appreciation of the dollar implied by the regression. Unfortunately, this interpretation of the regression is wrong because it ignores the value of the constant term."

Nonetheless, the relevance of $\alpha$ has remained under-researched to date, and we are not aware of a paper that investigates the role of the constant in more detail or provides an interpretation for the estimates of $\alpha$.

Our motivation for speculative UIP in section 4.1 suggests that one should look beyond the question of whether the slope coefficient equals unity and also consider the intercept. We argued that offsetting effects between $\alpha$ and $\beta$ should exist and motivated to test whether $\beta=1-\alpha / \mu_{p}$ which corresponds to zero-profits from static trading positions in the foreign currency. Given that the hypothesized offsetting effects exist, exclusively focusing on $\beta$ leads to misestimation of profits generable from static foreign currency positions: excess returns, $E R$, will be overestimated (in absolute terms) due to neglecting the offsetting effect by $\alpha$.

Analogously, the assessment of carry-trade profitability might be spurious if the null of the speculative UIP test holds. If - as expected by carry-traders $-\beta<1$, the following can be said for $\overline{C T}$ : since $\overline{p^{\prime}}<0$ it follows from $\beta<1$ that $(\beta-1) \overline{p^{\prime}}>0$ but also that $\overline{\alpha^{\prime}}<0$, again highlighting the offsetting effects. Thus, one generates profits from $\beta$ being lower than unity, but profits are eroded by the constant, sometimes even leading to a loss despite $\beta<1$ (scenarios $2 \mathrm{a}$ and $5 \mathrm{a}$ ). If $\beta>1$ the reverse is true, but it is not necessarily the case that one makes a loss even though the strategy is motivated by trading on a $\beta<1$ (scenarios $2 \mathrm{~b}$ and $5 \mathrm{~b}$ ). Considering $\beta$ only, may lead to a spurious appraisal of carry-trade profitability and in particular to an overestimation of profits if $\beta<1$.

In general, disregarding $\alpha$ distorts the assessment of zero-profitability of currency speculation. Consequently, as shown in the next section, also the judgment of economic value based on trader inaction ranges will be distorted. 


\section{Assessment of Economic Value by Trader Inaction Ranges}

To assess the economic significance of excess returns we derive trader inaction ranges implied by limits to speculation. First, we directly follow Lyons (2001), subsequently we derive the inaction range bounds for the static trading approach and the carry-trade. We show for both strategies that disregarding $\alpha$ leads to overestimation of excess returns and potentially to spurious conclusions about the economic value of currency speculation.

\subsection{Inaction Range as Motivated by Lyons (2001)}

In this subsection we derive the trader inaction range following the verbal description of Lyons (2001), suggesting that excess returns and hence Sharpe ratios realizable from UIP deviations solely depend on $\beta$; he does neither consider the effect of $\alpha$ on excess returns nor the impact of $\beta$ on the standard deviation of profits. For a given forward premium, Sharpe ratios increase as $\beta$ deviates from unity. Traders only allocate speculative capital to currency strategies if Sharpe ratios exceed a certain threshold (as e.g. given by the long run performance of a buy-and-hold equity investment), implying that $\beta$ needs to deviate correspondingly far from unity to generate order flow. This logic suggests a range of trader inaction for $\beta$ s close to unity while capital could only be attracted if $\beta$ over- respectively undershoots the bounds of this range. In the following, we derive the inaction range bounds; some technical details are provided in appendix B.1.

Based on the excess return defined in equation (2), we present the Sharpe ratio and the corresponding trader inaction range only considering $\beta$ but disregarding $\alpha$, i.e. presuming $\alpha=0$. However, we account for $\beta$ when calculating the standard deviation of $E R_{t+1}$. The variance of excess returns is given by

$$
\sigma_{E R}^{2}=(\beta-1)^{2} \sigma_{p}^{2}+\sigma_{\varepsilon}^{2}+2(\beta-1) \operatorname{cov}_{p, \varepsilon}
$$

with $\sigma$ denoting the standard deviations and $\operatorname{cov}_{p, \varepsilon}$ the covariance of $p$ and $\varepsilon$. If the Fama-regression parameters are estimated by OLS, the residuals are orthogonal to the premium by assumption, i.e. $\operatorname{cov}_{p, \varepsilon}=0$. Setting $\alpha=0$ and combining equations (2) and (13), the Sharpe ratio can be written as

$$
S R^{E R, \alpha=0}=\frac{(\beta-1) \mu_{p}}{\sqrt{(\beta-1)^{2} \sigma_{p}^{2}+\sigma_{\varepsilon}^{2}}} .
$$

The numerator changes in proportion to $\mu_{p}$ as $\beta$ deviates from unity. However, $\beta$ also enters the denominator and the standard deviation increases as $\beta$ deviates from unity. Thus, for increasing deviations of $\beta$, the Sharpe ratio changes monotonically but only at a decreasing rate, and therefore, from a pure mathematical point of view, one could say that speculation is limited since the Sharpe ratio is bounded. It is an empirical matter whether the limiting Sharpe ratios as well as the associated $\beta$ s are economically reasonable.

From equation (14) one can derive the trader inaction range in terms of $\beta$, i.e. the $\beta$ s necessary to achieve a certain Sharpe ratio threshold, $S R_{t h}$, by rearranging and solving the resulting quadratic 
equation,

$$
\beta\left[S R_{t h}, \alpha=0\right]=\frac{ \pm S R_{t h} \sigma_{\varepsilon}}{\sqrt{\left(\mu_{p}^{2}-S R_{t h}^{2} \sigma_{p}^{2}\right)}}+1 .
$$

The $\beta$ for which the Sharpe ratio is zero, the center of the inaction range, $\beta^{c}[0, \alpha=0]$, is unity and therefore corresponds to the standardly hypothesized UIP value. Around this center, the upper and lower bound are symmetric, as suggested by Lyons (2001), with the width of the range increasing overproportionally with the Sharpe ratio threshold. Note that for very small $\left|\mu_{p}\right|$ extremely large Sharpe ratio thresholds may be necessary to define the bounds, or put differently, a given $S R_{t h}$ might be unreachable high.

\subsection{Inaction Range for the Static Trading Approach}

We now take the impact of $\alpha$ on excess returns explicitly into account as given in equation (2). Some technical details are provided in appendix B.2. The standard deviation can be taken from equation (13) since $\alpha$ as a constant has no impact on the variance. The Sharpe ratio therefore is

$$
S R^{E R}=\frac{\alpha+(\beta-1) \bar{p}}{\sqrt{(\beta-1)^{2} \sigma_{p}^{2}+\sigma_{\varepsilon}^{2}}} .
$$

Compared to presuming $\alpha=0$, a non-zero $\alpha$ affects the Sharpe ratio by a change proportional to the standard deviation. Given that offsetting effects between $\alpha$ and $(\beta-1) \mu_{p}$ exist, the Sharpe ratios implied by equation (16) will be lower than those from equation (14) where $\alpha$ was set to zero. Furthermore, the Sharpe ratio is not a monotonic function of $\beta$ anymore; while the Sharpe ratio is still bounded (with the same limits), the Sharpe ratio does not converge to its extremes with $\beta$ approaching plus or minus infinity, rather the global optimum occurs when $\beta=\left(\mu_{p} \sigma_{\varepsilon}\right) /\left(\alpha \sigma_{p}\right)+1$.

For a given Sharpe ratio threshold, $S R_{t h}$, the respective $\beta$-bounds of the inaction range can be calculated from rearranging equation (16) and solving the resulting quadratic equation. The bounds are given by

$$
\beta\left[S R_{t h}, \alpha\right]=\frac{-\alpha \mu_{p} \pm S R_{t h} \sqrt{\alpha^{2} \sigma_{p}^{2}+\sigma_{\varepsilon}^{2}\left(\mu_{p}^{2}-S R_{t h}^{2} \sigma_{p}^{2}\right)}}{\mu_{p}^{2}-S R_{t h}^{2} \sigma_{p}^{2}}+1 .
$$

The center of the inaction range, i.e. the $\beta$ resulting in a Sharpe ratio of zero, corresponds to the $\beta$-value hypothesized in the speculative UIP test (Test 1) assessing the profitability of static foreign currency positions: $\beta^{c}[0, \alpha]=1-\alpha / \mu_{p}$. Hence, for non-zero values of $\alpha$, the inaction range is not centered around unity and, furthermore, the bounds are not symmetric around $\beta^{c}[0, \alpha]$. There might also be situations in which the Sharpe ratio threshold is unreachable high, resulting in the inaction range to be undefined.

Comparing the bounds derived with $\alpha=0$ to those derived using the Fama- $\alpha$, a misinterpretation of economic significance might arise due to the fact that the former differ from the latter in terms of the level of the inaction range (different centers) as well with respect to its shape (symmetric vs. asymmetric). Accordingly, we formulate the following prediction. 
PREDiCTION 1: Disregarding a leads to overestimation of excess returns and consequently to inaccurate trader inaction ranges for the static trading approach. If offsetting effects between $\alpha$ and $\beta$ exist (Test 1), the economic value generated by the static trading approach is overstated.

\subsection{Inaction Range for the Carry-Trade}

The excess return from the carry-trade was presented in equation (12), the corresponding variance is given by

$$
\sigma_{C T}^{2}=\sigma_{\alpha^{\prime}}^{2}+(\beta-1)^{2} \sigma_{p^{\prime}}^{2}+\sigma_{\varepsilon^{\prime}}^{2}+2(\beta-1) \operatorname{cov}_{\alpha^{\prime}, p^{\prime}}+2 \operatorname{cov}_{\alpha^{\prime}, \varepsilon^{\prime}}+2(\beta-1) \operatorname{cov}_{p^{\prime}, \varepsilon^{\prime}} .
$$

Note that if the sign of the premium changes at least once, $\alpha^{\prime}$ is not a constant and therefore also affects the standard deviation of carry-trade returns. Furthermore, the covariances can be different from, although will typically be close to, zero. The Sharpe ratio of the carry-trade is given by $S R^{C T}=$ $\overline{C T} / \sigma_{C T}$.

The bounds of the carry-trade inaction range for a given Sharpe ratio threshold can be calculated from rearranging $S R^{C T}$ and solving the following quadratic equation:

$$
\begin{aligned}
& (\beta-1)^{2}\left\{{\overline{p^{\prime}}}^{2}-S R_{t h}^{2} \sigma_{p^{\prime}}^{2}\right\}+(\beta-1)\left\{2\left(\overline{\alpha^{\prime} p^{\prime}}+\overline{p^{\prime} \varepsilon^{\prime}}-S R_{t h}^{2}\left(\operatorname{cov}_{\alpha^{\prime}, p^{\prime}}+\operatorname{cov}_{p^{\prime}, \varepsilon^{\prime}}\right)\right)\right\} \\
& +\left\{{\overline{\alpha^{\prime}}}^{2}+{\overline{\varepsilon^{\prime}}}^{2}+2 \overline{\alpha^{\prime} \varepsilon^{\prime}}-S R_{t h}^{2}\left(\sigma_{\alpha^{\prime}}^{2}+\sigma_{\varepsilon^{\prime}}^{2}+2 \operatorname{cov}_{\alpha^{\prime}, \varepsilon^{\prime}}\right)\right\} .
\end{aligned}
$$

The center of the inaction range is given by $\beta^{c}[0, \alpha]=1-\left(\overline{\alpha^{\prime}}+\overline{\varepsilon^{\prime}}\right) / \overline{p^{\prime}}$, corresponding to the value hypothesized in Test 3 for assessing whether the carry-trade yields non-zero profits. Note that the center of the range can be different from unity even if $\alpha=0$. Analogously to the inaction range derived for the static approach, the bounds can be asymmetric.

Disregarding $\alpha$ by presuming the constant, and thereby also the corresponding covariances, to be zero, again affects the judgement of economic significance. The centers of the respective inaction ranges differ by $\beta^{c}[0, \alpha]-\beta^{c}[0, \alpha=0]=-\overline{\alpha^{\prime}} / \overline{p^{\prime}}$. If offsetting effects between $\alpha$ and $(\beta-1) \mu_{p}$ exist, one finds that $\beta^{c}[0, \alpha]<\beta^{c}[0, \alpha=0]$ if $\beta<1$ and $\beta^{c}[0, \alpha]>\beta^{c}[0, \alpha=0]$ if $\beta>1$. Given our arguments and previous empirical evidence that $\beta$ is typically less than unity, neglecting $\alpha$ potentially results in an inaction range on a too high level and spurious indication of economic significance. Furthermore, the inaction range accounting for $\alpha$ is wider than the range based on $\alpha=0$; the magnitude of this effect depends on how often $\alpha^{\prime}$ changes signs. Based on these arguments we state the following prediction.

Prediction 2: If $\beta<1$, disregarding $\alpha$ leads to an overestimation of carry-trade profits, underestimation of their variance, and consequently to inaccurate trader inaction ranges. If offsetting effects between $\alpha$ and $\beta$ exist (Test 1), the economic value generated by carry-trades is overstated.

In addition to bilateral carry-trades, we also assess the economic value yielded by carry-trade portfolios. The first portfolio is an equally-weighted combination of bilateral carry-trades, the second maximizes the Sharpe ratio. When generating expected excess returns as inputs for the latter, we aim at mimicing market participants' behavior to condition their carry-trade investment decisions on the forward premium only. A consistent way of doing so is to assume that the exchange rate follows a 
random-walk without drift, implying that its expected change is zero, resulting in the expected excess return being equal to minus the forward premium. The portfolio is rebalanced every month. With respect to estimation, we consider a pooled regression framework and a fixed effects model. The excess returns, standard deviations, and inaction range bounds can be calculated as described for the bilateral carry-trade above: for a portfolio covering a spectrum of $i=1, \ldots, N$ foreign currencies with weights $\omega_{i}$, equation (12) is applied with $\alpha^{\prime}=\sum_{i=1}^{N} \omega_{i} \alpha_{i}^{\prime},\left(p_{t}^{1}\right)^{\prime}=\sum_{i=1}^{N} \omega_{i}\left(p_{t}^{1}\right)_{i}^{\prime}$, and $\varepsilon^{\prime}=\sum_{i=1}^{N} \omega_{i} \varepsilon_{i}^{\prime}{ }^{6}$

\section{Empirical Analysis}

For our empirical analysis we use monthly spot exchange rates and one-month forward premia provided by the Bank for International Settlements. The exchange rates considered are the US Dollar versus the Canadian Dollar (CAD), Swiss Franc (CHF), British Pound (GBP), Japanese Yen (JPY), Danish Krone (DKK), and German Mark (DEM) which is replaced by the Euro (EUR) from 1999 onwards. For the combined DEM-EUR series the data covers the period from December 1978 to September 2008, for all other currencies September 1977 to September 2008. As the sample stretches out into the current financial market crisis, we frequently compare full-sample results to results based only on data until the end of 2005 in section 6.1. Further robustness checks are provided in section 6.2, section 6.3 briefly summarizes our results and discusses potential routes for future research.

\subsection{Results}

\subsubsection{Speculative UIP, Risk-Premia, and Dynamics of Speculation}

The first rows of Table 1 display the results of the Fama-regression (1) as commonly reported in previous literature. $\alpha$ and $\beta$ are the parameter estimates with heteroscedasticity and autocorrelation consistent standard errors in parentheses; standard errors are calculated following Newey and West (1987). All estimates of $\beta$ are negative, and $\beta=1$ is rejected at the 1 percent level for all currencies. Evidence is mixed for the hypothesis $\alpha=0$ : while it cannot be rejected for CAD and DEM-EUR, it is rejected at the 10 percent level for GBP (p-value is 0.0797 ), at the 5 percent level for the CHF, and at the 1 percent level for the JPY. The joint hypothesis that $\alpha=0$ and $\beta=1$ is rejected at least at the 5 percent level for all currencies. Thus, consistent with previous research, standard tests do not support UIP. In contrast, applying Test $1, \beta=1-\alpha / \mu_{p}$, to assess whether UIP holds in a speculative sense, does not reject UIP in a single case. This indicates that the hypothesized offsetting relationship between $\alpha$ and $(\beta-1) \mu_{p}$ exists, implying that average excess returns are not significantly different from zero. The offsetting relationship between the two components of the average excess return is also illustrated in Figure 1 by plotting the extent to which $\alpha$ and $(\beta-1) \mu_{p}$ contribute to average excess returns in a stacked column diagram. The economic importance of $\alpha$ is indicated by the absolute magnitude of the component in average excess returns ranging from 31 to 49 percent. Its relevance is particularly highlighted by the very high t-statistics of testing the null hypothesis that the means of

\footnotetext{
${ }^{6}$ Note that for the pooled regression approach $\alpha_{i}$ is the same across all currencies and differences in $\alpha_{i}^{\prime}$ only stem from the signing by the forward premium, i.e. by the ', whereas for the fixed effects model the $\alpha_{i}$ differ for each $i$.
} 
the $(\beta-1) p_{t}^{1}$ series are zero. Hence, excess returns appear significantly non-zero when disregarding $\alpha$ whereas accounting for $\alpha$ reveals that they are insignificant.

The existence of these offsetting effects forms the basis for the spot rate process as given in equation (4). The underlying exchange rate dynamics allow for time-varying deviations from UIP and are consistent with a variety of exchange rate modeling approaches established in the literature; see our discussion in section 4.1. Our empirical results strongly support that exchange rate changes follow the forward premium in their core but additionally carry a component that depends on the extent to which the current forward premium deviates from its long-run mean. All estimates of $\alpha_{2}$ are significantly different from zero at the 1 percent level and the restriction of $\alpha_{1}=-\alpha_{2}$ cannot be rejected for any currency. Our results show that the standard - yet, to date, rather unsuccessful - argument that the forward bias puzzle reported in the literature is caused by an omitted risk-premium is indeed valid.

Assessing the profitability of carry-trade excess returns as proposed in Test 3, reveals mixed evidence: excess returns are significantly different from zero for CAD, GBP, and DEM-EUR, while not so for the CHF and JPY.

The existence of offsetting effects between $\alpha$ and $\beta$, as supported by the results of Test 1 , allows to illustrate the dynamics of excess returns from the static trading approach $(E R)$ and the carry-trade $(C T)$ by enumerating all possible scenarios which depend on the sign of $\mu_{p}$, the relation between $p_{t}^{1}$ and $\mu_{p}$ and the combination of $\beta$ and $\alpha$ values; see sections 4.1 and 4.2. Since the Fama- $\beta$ estimates are consistent with our priors - below unity for all currencies, only scenarios 1a to 6a are relevant. For the static trading approach, Panel A of Table 2 lists the predicted signs of excess returns for each scenario in the first column and reports the corresponding realizations in the remaining columns. The results show that the excess returns are signed as predicted. Furthermore, Panel A reports the performance of a static long position in the foreign currency as well as corresponding results for the perfect foresight strategy i.e. the performance if one had knowledge about $\mu_{p}$ and could therefore perfectly predict the next period scenario. The performance of the perfect foresight strategy is quite similar across all currencies with Sharpe ratios ranging from 0.52 to 0.73. In Panel B, analogous results are reported for the carry-trade. First, we find that the realized excess returns are signed as predicted. Second, the performance of carry-trades is mixed with Sharpe ratios varying between 0.27 to 0.55 . Comparing these figures to the performance of the perfect foresight strategy underpins that the latter dominates and that the carry-trade can be viewed as a simple proxy for it. Nevertheless, it also shows that carrytrades can be rationalized as they successfully collect risk-premia. Also note, that the finding that the foresight strategy, which is based on information about long-run interest rates, performs better is consistent with the literature showing that the term-structure of forward premia contains useful information for predicting exchange rates; see e.g. Clarida and Taylor (1997), Clarida et al. (2003), and Boudoukh et al. (2006).

\subsubsection{Economic Value of Bilateral Currency Speculation}

To assess the economic significance of UIP deviations, we report trader inaction ranges for the static trading approach in Table 3. In a first step, we use the full sample up to September 2008 and derive 
trader inaction ranges based on a Sharpe ratio threshold of 0.5, which Lyons (2001) argues to be reasonable since the long-run performance of a simple buy-and-hold strategy in US equity is around 0.4. ${ }^{7}$ The first rows repeat the Fama regression estimates with corresponding Newey and West (1987) standard errors in square brackets. Next, we report the bounds of the trader inaction range when disregarding $\alpha$, i.e. presuming $\alpha=0$. $\beta^{u}$ denotes the upper bound, $\beta^{c}$ the center, and $\beta^{l}$ the lower bound of the inaction range. The values in parentheses are the p-values for testing whether $\beta$ is below the upper bound, whether the estimate is equal to the center of the range, and whether $\beta$ is above the lower bound. Details of the testing procedure can be found in Appendix C. The inaction ranges taking $\alpha$ into account are presented in the same way in the subsequent rows.

The lower and the upper bound derived when presuming $\alpha=0$ are symmetrically centered around $\beta^{c}=1$, while the bounds derived when using the Fama- $\alpha$ are centered asymmetrically around $\beta^{c}=$ $1-\alpha / \mu_{p}$, i.e. the hypothesized value of zero-profits from the static trading approach (Test 1 ). Note that the latter bounds do not necessarily even contain the theoretical UIP value of unity. In particular, the results based on the bounds calculated with $\alpha=0$ suggest that zero Sharpe ratios are always rejected and even indicate a significant violation of the lower bound for the JPY, pointing at an economically significant Sharpe ratio. Incorporating the Fama- $\alpha$ into the assessment reveals that this finding is spurious, since for no currency the $\beta$ is found to be different from the center of the range and, accordingly, $\beta$ s are always within the inaction range bounds. The finding of whether $\beta$ is within the inaction range calculated with $\alpha=0$ or the Fama- $\alpha$ is summarized in the last three rows by indicating whether $\beta=\beta^{c}$ is rejected (R.) or not rejected (N.) and whether $\beta$ is inside (I.) or outside (O.) the lower bound and the upper bound.

A similar picture evolves when looking at the carry-trade results in Table 4. The inaction range bounds for $\alpha=0$ and the Fama- $\alpha$ respectively differ in level and shape resulting in an inaccurate assessment of economic value if $\alpha$ is disregarded. When setting $\alpha=0$, zero Sharpe ratios are rejected for all currencies, while this is only the case for CAD, GBP, and DEM-EUR when taking $\alpha$ into account. With respect to the lower bound, the results with $\alpha=0$ indicate a violation of the lower bound for the JPY thereby suggesting an economically significant Sharpe ratio. Taking account of the Fama- $\alpha$ reveals that for none of the currencies $\beta$ violates the inaction range bounds, again supporting the importance of considering the regression constant when evaluating economic significance.

Our inaction range results for the static trading approach as well as the carry-trade are in favor of our argument that disregarding $\alpha$ may lead to an inaccurate assessment of economic value. As we only find pronounced evidence for the JPY in both cases, one might at a first glance be tempted to consider this a JPY-specific phenomenon, though. One has to bear in mind, however, that the sample stretches until September 2008 and hence out into the current crisis period in which carry-trade profitability has been greatly reduced. As a consequence, for a given Sharpe ratio threshold of 0.5, economic significance may not be found independent of whether inaction ranges are calculated accurately or not, but just because of the low performance of carry-trades relative to the threshold itself. We therefore report carry-trade inaction ranges using only data up to December 2005 in Table 5 . The results based on

\footnotetext{
${ }^{7}$ Lyons (2001), p. 215, states "[...] I feel safe in asserting that there is limited interest at these major institutions in allocating capital to strategies with Sharpe ratios below $0.5 . "$.
} 
$\alpha=0$ indicate a violation of the lower bound for three out of the five currencies: CAD, GBP, and JPY. Taking account of the Fama- $\alpha$ reveals that for none of the currencies $\beta$ violates the inaction range bounds and hence - based on the threshold of 0.5 - one would not view bilateral carry-trades as yielding economic value.

Our arguments are further strengthend by comparing results across different Sharpe ratio thresholds. While we used the value of 0.5 proposed by Lyons (2001) as an anchor point, the particular choice of threshold applied for judging economic value depends on a market participant's risk appetite. We calculate inaction range bounds for the static trading approach and the carry trade for a range of Sharpe ratio thresholds for the full sample as well as using only data until the end of 2005. Figure 2 plots the number of currencies for which economic value is indicated for a given Sharpe ratio threshold depending on whether bounds are calculated based on $\alpha=0$ (plotted in gray) or the Fama- $\alpha$ (black). For both sample periods, the static trading approach results based on $\alpha=0$ indicate that economic value is generated for at least three currencies up to a Sharpe ratio threshold of 0.3 and for one currency (JPY) even beyond 0.5. Accounting for $\alpha$ reveals that none of the Sharpe ratios is different from zero. Analoguously, assessing the economic value of carry-trades by inaction ranges based on $\alpha=0$ suggests that Sharpe ratio thresholds of up to 0.8 can be outperformed. Accounting for $\alpha$ reveals that none of the bilateral carry-trades provides economic value for Sharpe thresholds higher than 0.4.

The above results provide strong support for our predictions that disregarding $\alpha$ leads to an overestimation of profits for the static trading approach (Prediction 1) as well as the carry-trade (Prediction 2 ), hence to inaccurate inaction ranges, and consequently to an incorrect assessment of economic value.

8 Our findings suggest that Sharpe ratios from the static trading approach are zero and that carrytrades do not provide economic value for thresholds larger than 0.4. These results are consistent with the Lyons (2001) concept of limits to speculation and in line with the conclusion of Sarno et al. (2006) that the forward bias in bilateral exchange rates is economically small. Recent research, however, provides evidence that the performance of carry-trade strategies improves substantially when creating portfolios across currencies, see e.g. Burnside et al. (2008). Della Corte et al. (2008) show that economic value can be generated by conditioning on the forward premium in dynamic multi-currency portfolio strategies. To supplement these findings, we present empirical results for the economic value of carry-trade portfolios in the next subsection.

\subsubsection{Economic Value of Carry-Trade Portfolios}

As described in section 5.3, we estimate inaction ranges for an equally weighted portfolio and a Sharpe ratio maximizing portfolio based on a pooled regression approach and a fixed effects model. The upper part of Table 6 reports model estimates of $\alpha$ and $\beta$ for the full sample and for the sample until end of 2005. p[FE vs. pooled] is the p-value for the F-statistic of testing whether the pooled regression model performs equally well as the fixed effects model; for both samples we find that the fit of the fixed effects model is significantly better. The lower part of the table reports the inaction ranges for the

\footnotetext{
${ }^{8}$ As mentioned in Prediction 2, disregarding $\alpha$ when assessing the economic value of carry-trades also leads to an underestimation of the variance of profits; empirically this effect is relatively small, though.
} 
two portfolios calculated with the Fama- $\alpha$. In general, the portfolio inaction ranges based on a Sharpe ratio threshold of 0.5 are tighter than those reported for bilateral carry-trades above which reflects the better risk-return profile of the portfolios. The results based on the pooled regression model indicate that profits of both portfolios are economically significant as judged by a Sharpe ratio threshold of 0.5. The results of the fixed effects model suggest that economic value is only generated by the optimal portfolio. As the F-statistics clearly indicate that the fixed effects model dominates the pool regression approach, we concentrate on the former in our subsequent analysis.

To analyze the economic value attainable from carry-trade portfolios and the consequences of disregarding $\alpha$, we plot Sharpe ratio thresholds against the p-values at which they are outperformed significantly in Figure 3. With Sharpe ratio thresholds along the the x-axis and corresponding p-vales along the y-axis, the upper line represents p-values when accounting for $\alpha$, the lower line represents p-values when presuming $\alpha=0$. The plots show that the p-value for a given Sharpe ratio threshold is much lower when disregarding $\alpha$ thereby indicating a too high level of economic significance. The tables below the graphs list the Sharpe ratio thresholds which are significantly outperformed at p-values of $0.01,0.05$, and 0.1 , showing that disregarding $\alpha$ leads to an overestimation of Sharpe ratios by 0.53 to 0.59 . Nevertheless, the results also show that the optimal portfolio generates economic value as Sharpe ratios are significantly larger than 0.5. This finding is line with the results of Della Corte et al. (2008) and with market evidence that carry-trade strategies are hugely popular among practiconers; see e.g. Galati and Melvin (2004) who show that the use of carry-trades are key driver of the surge in foreign exchange trading in recent years.

\subsection{Robustness Checks}

With respect to the robustness of our results we examine whether our conclusions remain the same when investigating other currencies, other forward-maturities, or other sample periods. These results support the findings presented above and therefore, to save space, we prefer for most to just summarize them instead of providing full tables. Detailed results are available upon request.

Apart from the currencies reported in the paper, we have also analyzed a variety of others such as the Australian Dollar and New Zealand Dollar (which have been excluded because of short data availability), other European non-Euro currencies (e.g. Norwegian Krone, Swedish Krone), and further European pre-Euro currencies (e.g. French Franc, Italian Lira). The conclusions that can be drawn for these currencies are qualitatively equivalent to those reached in the paper.

Second, our conclusions are independent of the choice of forward rate maturity. The Bank for International Settlements also provides data for three, six, and twelve month horizons. ${ }^{9}$ Repeating the analysis for this data, results are qualitatively the same.

Finally, our findings are robust over time. We did the whole empirical analysis on various subsamples and conclusions are qualitatively the same; these results are omitted from the paper to save space but are available on request. To provide further evidence for the relevance of considering $\alpha$ in the

\footnotetext{
${ }^{9}$ In the context of analyzing different maturities, it is worth mentioning that carry-trades are typically based on (rolling over) short-term contracts since liquidity is higher than for longer maturities.
} 
assessment of economic value, we graph the Fama- $\beta$ as well as the inaction ranges based on $\alpha=0$ and the Fama- $\alpha$ for the carry-trade in Figure 4. The plots are based on 60 -month rolling estimates using a Sharpe ratio threshold of 0.5 . The graphs illustrate that disregarding $\alpha$ distorts the evaluation of the economic significance of speculation profits. While the rolling Fama- $\beta$ s often seem to undershoot the lower bound when calculating the inaction range with $\alpha=0$, this is merely true when accurately taking account of the Fama- $\alpha$. This suggests that our conclusions of limited economic value for bilateral carry-trades is not particular to the sample period chosen.

Figure 5 plots the inaction range bounds for the equally-weighted and the Sharpe ratio maximizing portfolio estimated with the fixed effects model using $\alpha=0$ and the Fama- $\alpha$ respectively. The resulting pictures are similar to those of the bilateral carry-trade in that the shape of the bounds accounting for $\alpha$ looks very different from those based on disregarding $\alpha$. For the latter the $\beta$ undershoots the lower bound by far most of the time for both portfolios. Based on the bounds that account for $\alpha$, the rolling $\beta$ is very close to the lower bound and often inside the inaction range for the equally-weighted portfolio. For the optimal portfolio, $\beta$ is outside the inaction range most of the time, pointing at the potential to generate economic value, however, at a lower scale as suggested by the bounds based on $\alpha=0$. Hence, the robustness checks support our findings and strengthen our conclusions.

\subsection{Summary of Results and Routes for Future Research}

Our empirical results strongly support that UIP holds in a speculative sense and that exchange rate dynamics comprise a time-varying risk-premium in addition to the forward premium. The forward bias puzzle reported in previous research originates from the omission of this risk-premium in standard UIP tests. While the carry-trade strategy collects risk-premia, its economic value is small on a bilateral basis, however, carry-trade portfolios have the potential to generate economic value. Disregarding $\alpha$ leads to overstating the economic value of currency speculation. Overall, our results are in line with recent research and consistent with market evidence that financial institutions routinely apply forward bias strategies.

A particularly nice feature of the framework developed in our paper is that it can be directly applied to the standard Fama-regression setup. Hence, it equips the large research community working on related studies with an effective testing procedure which is straight-forward in its implementation and provides material information about the economic relevance of UIP deviations. Moreover, there are various directions in which one can extend the analysis of the paper: A possible extension - which was beyond the scope of the present paper - is to explicitly model the stochastic process of interest rates. As the risk-premium that emerges from our model is driven by the current and the long-run forward premium, it seems instructive to revisit multi-country term-structure models along the lines of e.g. Bansal (1997), Backus et al. (2001), and Brennan and Xia (2006). Another extension could be to model $\alpha$ and $\beta$ as time-varying coefficients which allows for a closer look at the relationship between the two parameters. Finally, the approach developed in this paper is not limited in its applicability to foreign exchange markets. The same idea can be extended to other markets for which a standard approach is to test expectations hypotheses or unbiasedness hypotheses. For instance, the same setting 
could be applied to (the closed economy) expectations hypothesis of interest rates potentially allowing for explanations to departures from the expectations hypothesis.

\section{Conclusion}

Tests of foreign exchange market efficiency are typically based on an assessment of uncovered interest rate parity (UIP) using the Fama-regression. Empirical research over the last decades consistently rejects the UIP condition and claims that the forward rate is a biased estimate of the future spot rate. Attempts to explain this forward bias puzzle, using a variety of (macro-oriented) models, tests, and data, have met with limited success. Recent (microstructure-motivated) research finds that order-flow drives exchange rates which suggests that scrutinizing the trading behavior of market participants may offer deeper insight into the nature and the economic relevance of the forward bias puzzle. Traders take up currency speculation strategies, and thereby produce order-flow, only if they expect resulting profits to provide economic value; otherwise they remain inactive and the unexploited forward bias may remain persistent.

In the present paper, we derived the dynamics and assessed the economic value of currency speculation by formalizing the concept of a trader inaction range. We derived a speculative pendant to the standard UIP condition and showed (i) that exchange rate returns comprise a time-varying risk-premium, (ii) how carry-traders are able to collect this risk-premium, thereby providing a direct rationale for the strategy, and (iii) that the forward bias puzzle originates from the omission of the risk-premium in standard UIP tests. Throughout our analysis, we emphasized that focusing on the slope coefficient but disregarding the interecept in the Fama-regression leads to overestimating excess returns and consequently to overstating the economic value of currency speculation.

Our empirical results strongly support that UIP holds in a speculative sense and that exchange rate dynamics comprise a time-varying risk-premium, the omission of which causes the forward bias in the Fama-regression. Carry-traders generate positive excess returns as predicted. Whereas the economic value of these excess returns is limited for bilateral carry-trades, multi-currency portfolio strategies indeed generate economic value. Overall, our results are in line with recent research and consistent with market evidence that financial institutions routinely apply forward bias strategies.

A particularly nice feature of our framework is that it can be directly applied to the standard Fama-regression setup. Hence, it equips the large research community working on related studies with an effective testing procedure which is straight-forward in its implementation and provides material information about the economic relevance of UIP deviations. Moreover, we have discussed various directions in which one can extend the analysis of our paper in future research, also beyond foreign exchange markets. 


\section{References}

Backus, D. K., Foresi, S., Telmer, C. I., 2001, "Affine Term Structure Models and the Forward Premium Anomaly," Journal of Finance, 56, 279-304.

Backus, D. K., Gregory, A. W., Telmer, C. I., 1993, "Accounting for Forward Rates in Markets for Foreign Currency," Journal of Finance, 48, 1887-1908.

Bansal, R., 1997, "An Exploration of the Forward Premium Puzzle in Currency Markets," Review of Financial Studies, 10, 369-403.

Bansal, R., Gallant, A. R., Hussey, R., Tauchen, G., 1995, "Non-Parametric Estimation of Structural Models for High Frequency Currency Market Data," Journal of Econometrics, 66, 251-287.

Barnhart, S. W., McNown, R., Wallace, M. S., 1999, "Non-Informative Tests of the Unbiased Forward Exchange Rate," Journal of Financial and Quantitative Analysis, 34, 265-291.

Bekaert, G., 1996, "The Time-Variation of Risk and Return in Foreign Exchange Markets: A General Equilibrium Perspective," Review of Financial Studies, 9, 427-470.

Bekaert, G., Hodrick, R. J., 1993, "On Biases in the Measurement of Foreign Exchange Risk Premiums," Journal of International Money and Finance, 12, 115-138.

Bekaert, G., Hodrick, R. J., 2001, "Expectations Hypotheses Tests," Journal of Finance, 56, 13571394.

Bekaert, G., Hodrick, R. J., 2009, International Financial Management, Prentice-Hall.

Bekaert, G., Hodrick, R. J., Marshall, D., 1997, "The Implications of First-Order Risk Aversion for Asset Market Risk Premiums," Journal of Monetary Economics, 40, 3-39.

Bilson, J. F. O., 1981, "The Speculative Efficiency Hypothesis," Journal of Business, 54, 435-451.

Bjønnes, G. H., Rime, D., 2005, "Dealer Behavior and Trading Systems in Foreign Exchange Markets," Journal of Financial Economics, 75, 571-605.

Boudoukh, J., Richardson, M., Whitelaw, R., 2006, "The Information in Long-Maturity Forward Rates: Implications for Exchange Rates and the Forward Premium Anomaly," NBER Working Paper 11840.

Brennan, M., Xia, Y., 2006, "International Capital Markets and Foreign Exchange Risk," Review of Financial Studies, 19, 753-795.

Brenner, R. J., Kroner, K. F., 1995, "Arbitrage, Cointegration, and Testing the Unbiasedness Hypothesis in Financial Markets," Journal of Financial and Quantitative Analysis, 30, 23-42.

Brunnermeier, M., Nagel, S., Pedersen, L., 2008, "Carry Trades and Currency Crashes," NBER Macroeconomics Annual, 23.

Burnside, C., Eichenbaum, M., Kleshehelski, I., Rebelo, S., 2006, "The returns to currency speculation," NBER Working Paper No. W12489, Cambridge, MA.

Burnside, C., Eichenbaum, M., Rebelo, S., 2008, "Carry Trade: The Gains of Diversification," Journal of the European Economic Association, 6, 581-588.

Clarida, R. H., Sarno, L., Taylor, M. P., Valente, G., 2003, "The Out-of-Sample Success of Term Structure Models as Exchange Rate Predictors: A Step Beyond," Journal of International Economics, $60,61-83$.

Clarida, R. H., Taylor, M. P., 1997, "The Term Structure of Forward Exchange Premiums and the Forecastability of Spot Exchange Rates: Correcting the Errors," Review of Economics and Statistics, $79,353-361$. 
Cumby, R. E., 1988, "Is It Risk? Explaining Deviations from Uncovered Interest Parity," Journal of Monetary Economics, 22, 279-299.

Della Corte, P., Sarno, L., Tsiakas, I., 2008, "An Economic Evaluation of Empirical Exchange Rate Models," Review of Financial Studies, forthcoming.

Deutsche Bank, 2004, "Forward Rate Bias: What it is," Global Markets Research.

Dominguez, K., Panthaki, F., 2006, "What Defines 'News' in Foreign Exchange Markets?," Journal of International Money and Finance, 25, 168-198.

Domowitz, I., Hakkio, C., 1985, "Conditional Variance and the Risk Premium in the Foreign Exchange Market," Journal of International Economics, 19, 47-66.

Engel, C., 1996, "The Forward Discount Anomaly and the Risk Premium: A Survey of Recent Evidence," Journal of Empirical Finance, 3, 132-192.

Engel, C., Hamilton, J., 1990, "Long swings in the dollar: are they in the data and do markets know it?," American Economic Review, 80, 689-713.

Evans, M. D. D., Lyons, R. K., 2002, "Order Flow and Exchange Rate Dynamics," Journal of Political Economy, 110, 170-180.

Evans, M. D. D., Lyons, R. K., 2004, "A new Micro Model of Exchange Rate Dynamics," NBER Working Paper 10379.

Evans, M. D. D., Lyons, R. K., 2006, "Understanding Order Flow," International Journal of Finance and Economics, 11, 3-23.

Fama, E. F., 1984, "Forward and Spot Exchange Rates," Journal of Monetary Economics, 14, 319-338.

Farhi, E., Gabaix, X., 2008, "Rare Disasters and Exchange Rates," Harvard University, Working Paper.

Frankel, J. A., Engel, C., 1984, "Do Asset Demand Functions Optimize Over the Mean and Variance of Real Returns? A Six Currency Test," Journal of International Economics, 17, 309-323.

Froot, K. A., Thaler, R. H., 1990, "Anomalies: Foreign Exchange," The Journal of Economic Perspectives, 4, 179-192.

Galati, G., Heath, A., McGuire, P., 2007, "Evidence of carry trade activity," BIS Quarterly Review, pp. $27-41$.

Galati, G., Melvin, M., 2004, "Why has FX Trading Surged? Explaining the 2004 Triennial Survey," BIS Quarterly Review, pp. 67-74.

Greene, W. H., 2003, Econometric Analysis, Prentice Hall, New Jersey, 5 edn.

Hansen, L. P., Hodrick, R. J., 1980, "Forward Exchange Rates as Optimal Predictors of Future Spot Rates: An Econometric Analysis," Journal of Political Economy, 88, 829-853.

Hochradl, M., Wagner, C., 2008, "Trading the Forward Bias: Are there Limits to Speculation?," European Finance Association 2006 Zurich Meetings Paper.

Hodrick, R., 1992, "An Interpretation of Foreign Exchange Market Efficiency Test," Northwestern University, mimeo.

Hodrick, R. J., 1987, The Empirical Evidence on the Efficiency of Forward and Futures Foreign Exchange Markets, Harwood.

Ito, T., Lyons, R. K., Melvin, M. T., 1998, "Is There Private Information in the FX Market? The Tokyo Experiment," Journal of Finance, pp. 1111-1130. 
Jurek, J. W., 2008, "Crash-neutral Currency Carry Trades," Princeton University, Working Paper.

Lewis, K. K., 1995, "Puzzles in International Financial Markets," In: G. M. Grossman, K. Rogoff (Eds.), , vol. 3, . pp. 1913-1971, Elsevier North Holland, Amsterdam.

Lustig, H., Verdelhan, A., 2007, "The Cross-Section of Currency Risk Premia and US Consumption Growth Risk," American Economic Review, 97, 89-117.

Lyons, R. K., 1995, "Tests of Microstructural Hypotheses in Foreign Exchange Markets," Journal of Financial Economics, 39, 321-351.

Lyons, R. K., 2001, The Microstructure Approach to Exchange Rates, MIT Press.

Lyons, R. K., 2002, "Foreign Exchange: Macro Puzzles, Micro Tools," Economic Review, Federal Reserve Bank of San Francisco, pp. 51-69.

Mark, N. C., 1988, "Time Varying Betas and Risk Premia in the Pricing of Forward Foreign Exchange Contracts," Journal of Financial Economics, 22, 335-354.

Newey, W., West, K., 1987, "A Simple Positive Semi-Definite, Heteroscedasticity and Autorcorrelation Consitent Covariance Matrix," Econometrica, 55, 703-708.

Rime, D., 2001, "US Exchange Rates and Currency Flows," Mimeo Stockholm Institute for Financial Research.

Rime, D., Sarno, L., Sojli, E., 2008, "Exchange Rate Forecasting, Order Flow and Macroeconomic Information," Norges Bank Working Paper.

Sarno, L., 2005, "Towards a Solution to the Puzzles in Exchange Rate Economics: Where Do We Stand?," Canadian Journal of Economics, 38, 673-708.

Sarno, L., Valente, G., Leon, H., 2006, "Nonlinearity in Deviations from Uncovered Interest Parity: An Explanation of the Forward Bias Puzzle," Review of Finance, 10, 443-482.

Taylor, M. P., 1995, "The Economics of Exchange Rates," Journal of Economic Literature, 33, 13-47.

Taylor, M. P., Sager, M., 2008, "Commercially Available Order Flow Data and Exchange Rate Movements: Caveat Emptor," Journal of Money, Credit and Banking, 40, 583-625.

Verdelhan, A., 2008, "A Habit-Based Explanation of the Exchange Rate Risk Premium," Journal of Finance, forthcoming.

Villanueva, O. M., 2007, "Forecasting Currency Excess Returns: Can the Forward Bias be Exploited?," Journal of Financial and Quantitative Analysis, 42, 963-990.

Zivot, E., 2000, "Cointegration and Forward and Spot Exchange Rate Regressions," Journal of International Money and Finance, 19, 785-812. 
Table 1: Uncovered Interest Parity

\begin{tabular}{|c|c|c|c|c|c|}
\hline & CAD & CHF & $\overline{\mathrm{GBP}}$ & 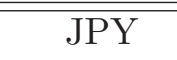 & DEM-EUR \\
\hline \multicolumn{6}{|l|}{ Fama-regression } \\
\hline$\alpha$ & $\begin{array}{c}-0.0006 \\
(0.0010)\end{array}$ & $\begin{array}{c}0.0056 \\
(0.0028)\end{array}$ & $\begin{array}{r}-0.0033 \\
(0.0019)\end{array}$ & $\begin{array}{c}0.0100 \\
(0.0027)\end{array}$ & $\begin{array}{c}0.0021 \\
(0.0020)\end{array}$ \\
\hline$\beta$ & $\begin{array}{c}-0.9858 \\
(0.4728)\end{array}$ & $\begin{array}{c}-1.2915 \\
(0.7288)\end{array}$ & $\begin{array}{c}-2.1322 \\
(1.0570)\end{array}$ & $\begin{array}{c}-2.4954 \\
(0.7205)\end{array}$ & $\begin{array}{r}-1.0907 \\
(0.7979)\end{array}$ \\
\hline \multicolumn{6}{|c|}{ Standard UIP Tests } \\
\hline $\mathrm{p}[\alpha=0]$ & {$[0.5510]$} & {$[0.0457]$} & {$[0.0797]$} & {$[0.0002]$} & {$[0.2996]$} \\
\hline $\mathrm{p}[\beta=1]$ & {$[0.0000]$} & {$[0.0018]$} & {$[0.0032]$} & {$[0.0000]$} & [0.0092] \\
\hline $\mathrm{p}[\alpha=0, \beta=1]$ & {$[0.0000]$} & {$[0.0071]$} & {$[0.0130]$} & {$[0.0000]$} & {$[0.0317]$} \\
\hline \multicolumn{6}{|c|}{ Test 1 (Speculative UIP) } \\
\hline$\overline{\mathrm{p}}\left[\beta=1-\frac{\alpha}{\mu_{p}}\right]$ & {$[0.3947]$} & {$[0.7118]$} & {$[0.2867]$} & {$[0.7632]$} & {$[0.8341]$} \\
\hline \multicolumn{6}{|c|}{ Test 2 (Risk-Premia) } \\
\hline$\alpha_{1}$ & $\begin{array}{c}-0.0006 \\
(0.0010)\end{array}$ & $\begin{array}{c}0.0056 \\
(0.0028)\end{array}$ & $\begin{array}{r}-0.0033 \\
(0.0019)\end{array}$ & $\begin{array}{c}0.0100 \\
(0.0027)\end{array}$ & $\begin{array}{c}0.0021 \\
(0.0020)\end{array}$ \\
\hline$-\alpha_{2}$ & $\begin{array}{c}-0.0013 \\
(0.0003)\end{array}$ & $\begin{array}{c}0.0063 \\
(0.002)\end{array}$ & $\begin{array}{c}-0.0049 \\
(0.0017)\end{array}$ & $\begin{array}{c}0.0106 \\
(0.0022)\end{array}$ & $\begin{array}{c}0.0025 \\
(0.0009)\end{array}$ \\
\hline $\mathrm{p}\left[\alpha_{1}=-\alpha_{2}\right]$ & {$[0.3947]$} & {$[0.7118]$} & {$[0.2867]$} & {$[0.7632]$} & [0.8341] \\
\hline $\mathrm{p}\left[\alpha_{2}=0\right]$ & {$[0.0000]$} & {$[0.0018]$} & {$[0.0032]$} & {$[0.0000]$} & {$[0.0092]$} \\
\hline \multicolumn{6}{|c|}{ Test 3 (CT Zero Profits) } \\
\hline $\mathrm{p}\left[\beta=1-\frac{\overline{\alpha^{\prime}}+\overline{\varepsilon^{\prime}}}{\overline{p^{\prime}}}\right]$ & {$[0.0011]$} & {$[0.4955]$} & {$[0.0239]$} & {$[0.2536]$} & {$[0.0437]$} \\
\hline
\end{tabular}

Notes: Results are for 09/1977-09/2008 for CAD, CHF, GBP, JPY, and 12/1978-09/2008 for the combined series of DEM (until 12/1998) and EUR (from 01/1999). The table reports the Fama-regression estimates of $\alpha$ and $\beta$ with heteroscedasticity and autocorrelation consistent standard errors, following Newey and West (1987), in parentheses. $\mu_{p}$ denotes the long run average of the forward premium. $\mathrm{p}[\cdot]$ denotes the p-value for testing the hypothesis formulated in [.]. The first three p-values are for standard hypotheses applied when testing UIP. Test 1 is the speculative UIP test that we proposed in section 4.1. Results related to Test 2 are estimates of regression (8) with standard errors in parantheses and p-values of relevant tests. Test 3 is applied to the Fama-regression (1) and investigates whether excess returns from carry-trades are significantly different from zero. Superscript ' indicates that a variable is adjusted for the position taken in the strategy; see (12) in section 4.2. $\varepsilon$ denotes the Fama-regression residual. 


\section{Table 2: Dynamics of Currency Speculation}

Panel A: Static Trading Approach (ER) and Perfect Foresight Strategy

\begin{tabular}{lrrrrr}
\hline \hline & CAD & CHF & GBP & JPY & DEM-EUR \\
Predicted sign vs. realized: & & & & & \\
scenario 1a - & & -0.0065 & & -0.0075 & -0.0043 \\
scenario 2a + & & 0.0072 & & 0.0056 & 0.0052 \\
scenario 3a + & & 0.0032 & & 0.0112 & 0.0060 \\
scenario 4a - & -0.0016 & & -0.0084 & & \\
scenario 5a - & -0.0012 & & -0.0010 & & \\
scenario 6a + & 0.0035 & & 0.0072 & & \\
& & & & & \\
Static long FC position: & & & & & \\
mean & 0.0007 & -0.0007 & 0.0017 & -0.0005 & -0.0004 \\
sd (p.a.) & 0.0163 & 0.0358 & 0.0307 & 0.0341 & 0.0315 \\
SR & 0.1524 & -0.0687 & 0.1877 & -0.0554 & -0.0407 \\
Perfect foresight strategy: & & & & & \\
mean & 0.0024 & 0.0063 & 0.0054 & 0.0071 & 0.0049 \\
sd (p.a.) & 0.0161 & 0.0352 & 0.0302 & 0.0334 & 0.0312 \\
SR & 0.5203 & 0.6147 & 0.6231 & 0.7326 & 0.5413 \\
\hline \hline
\end{tabular}

Panel B: Carry-Trade $(C T)$

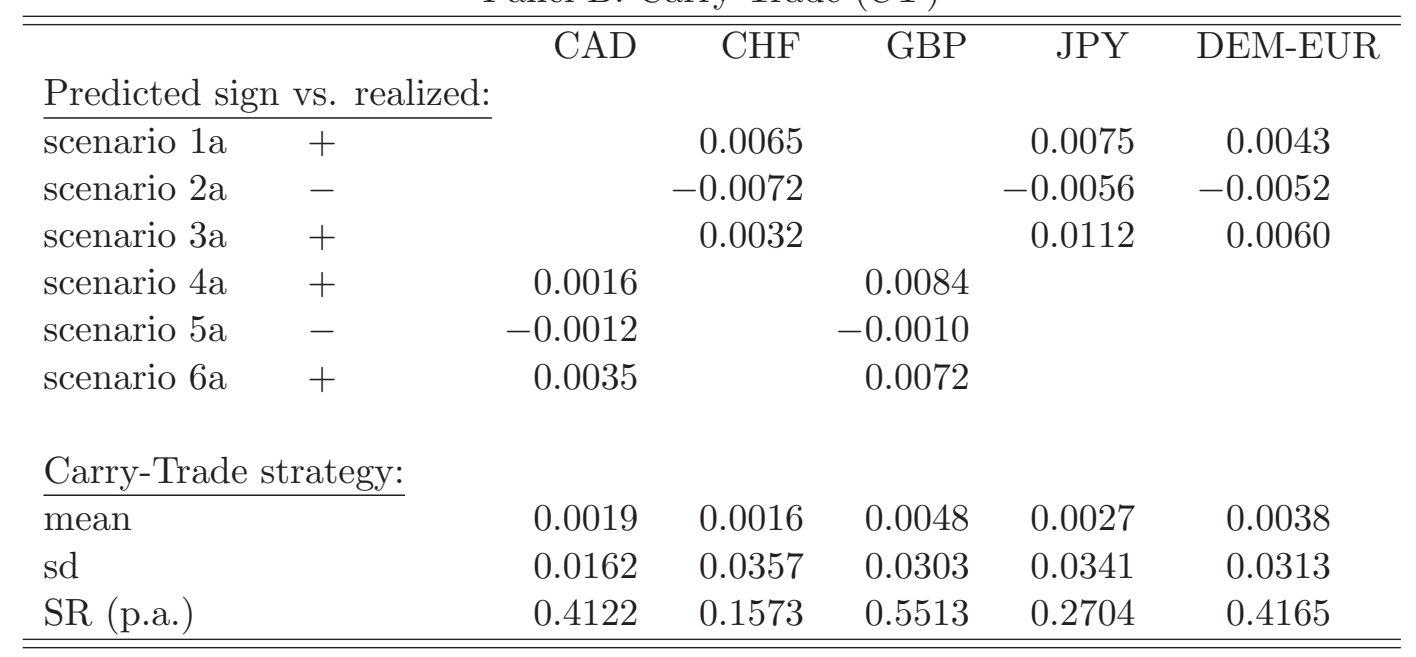

Notes: Results are for 09/1977-09/2008 for CAD, CHF, GBP, JPY, and 12/1978-09/2008 for the combined series of DEM (until 12/1998) and EUR (from 01/1999).

Panel A compares realized excess returns from the static trading approach $(E R)$ to the signs predicted for scenarios $1 \mathrm{a}$ to 6a; see section 4.1. Monthly mean and standard deviations as well as annualized Sharpe ratios are reported for a permanent long position in the foreign currency as well as for the prefect foresight strategy.

Panel B compares realized carry-trade excess returns $(C T)$ to the signs predicted for scenarios 1a to 6a; see section 4.2 . Furthermore, monthly mean and standard deviations as well as annualized Sharpe ratios of carry-trades are reported. 
Table 3: Trader Inaction Ranges for the Static Trading Approach

\begin{tabular}{|c|c|c|c|c|c|}
\hline & CAD & CHF & GBP & JPY & DEM-EUR \\
\hline \multicolumn{6}{|c|}{ Fama-regression } \\
\hline $\bar{\alpha}$ & $\begin{array}{c}-0.0006 \\
(0.0010)\end{array}$ & $\begin{array}{c}0.0056 \\
(0.0028)\end{array}$ & $\begin{array}{c}-0.0033 \\
(0.0019)\end{array}$ & $\begin{array}{c}0.0100 \\
(0.0027)\end{array}$ & $\begin{array}{c}0.0021 \\
(0.0020)\end{array}$ \\
\hline$\beta$ & $\begin{array}{r}-0.9858 \\
(0.4728)\end{array}$ & $\begin{array}{c}-1.2915 \\
(0.7288)\end{array}$ & $\begin{array}{c}-2.1322 \\
(1.057)\end{array}$ & $\begin{array}{c}-2.4954 \\
(0.7205)\end{array}$ & $\begin{array}{r}-1.0907 \\
(0.7979)\end{array}$ \\
\hline \multicolumn{6}{|c|}{ Bounds with $\alpha=0$} \\
\hline$\overline{\beta^{u}}$ & $\begin{array}{c}4.7784 \\
{[1.0000]}\end{array}$ & $\begin{array}{c}2.8733 \\
{[1.0000]}\end{array}$ & $\begin{array}{c}3.8047 \\
{[1.0000]}\end{array}$ & $\begin{array}{c}2.5900 \\
{[1.0000]}\end{array}$ & $\begin{array}{c}4.9571 \\
{[1.0000]}\end{array}$ \\
\hline$\beta^{c}$ & $\begin{array}{c}1.0000 \\
{[0.0000]}\end{array}$ & $\begin{array}{c}1.0000 \\
{[0.0018]}\end{array}$ & $\begin{array}{c}1.0000 \\
{[0.0032]}\end{array}$ & $\begin{array}{c}1.0000 \\
{[0.0000]}\end{array}$ & $\begin{array}{c}1.0000 \\
{[0.0092]}\end{array}$ \\
\hline$\beta^{l}$ & $\begin{array}{r}-2.7784 \\
{[0.9999]}\end{array}$ & $\begin{array}{r}-0.8733 \\
{[0.2832]}\end{array}$ & $\begin{array}{c}-1.8047 \\
{[0.3784]}\end{array}$ & $\begin{array}{c}-0.5900 \\
{[0.0043]}\end{array}$ & $\begin{array}{r}-2.9571 \\
{[0.9901]}\end{array}$ \\
\hline \multicolumn{6}{|c|}{ Bounds with Fama- $\alpha$} \\
\hline$\overline{\beta^{u}}$ & $\begin{array}{c}3.8109 \\
{[0.9996]}\end{array}$ & $\begin{array}{c}0.8181 \\
{[0.9987]}\end{array}$ & $\begin{array}{c}1.6831 \\
{[0.9999]}\end{array}$ & $\begin{array}{r}-0.7236 \\
{[0.9986]}\end{array}$ & $\begin{array}{c}3.0361 \\
{[0.9957]}\end{array}$ \\
\hline$\beta^{c}$ & $\begin{array}{c}0.1214 \\
{[0.3947]}\end{array}$ & $\begin{array}{r}-1.0326 \\
{[0.7118]}\end{array}$ & $\begin{array}{r}-1.0750 \\
{[0.2867]}\end{array}$ & $\begin{array}{c}-2.3152 \\
{[0.7632]}\end{array}$ & $\begin{array}{c}-0.7801 \\
{[0.8341]}\end{array}$ \\
\hline$\beta^{l}$ & $\begin{array}{r}-3.7723 \\
{[0.9675]}\end{array}$ & $\begin{array}{r}-2.9844 \\
{[0.9888]}\end{array}$ & $\begin{array}{r}-3.9836 \\
{[0.9630]}\end{array}$ & $\begin{array}{c}-3.9872 \\
{[0.9919]}\end{array}$ & $\begin{array}{r}-4.9705 \\
{[0.9875]}\end{array}$ \\
\hline \multicolumn{6}{|c|}{ Inference $\alpha=0 /$ Fama- $\alpha$} \\
\hline $\begin{array}{l}\overline{\beta^{u}} \\
\beta^{c} \\
\beta^{l}\end{array}$ & $\begin{array}{l}\text { I. / I. } \\
\text { R. / N. } \\
\text { I. / I. }\end{array}$ & $\begin{array}{l}\text { I. / I. } \\
\text { R. / N. } \\
\text { I. / I. }\end{array}$ & $\begin{array}{c}\text { I. / I. } \\
\text { R. / N. } \\
\text { I. / I. }\end{array}$ & $\begin{array}{c}\text { I. / I. } \\
\text { R. / N. } \\
\text { O. / I. }\end{array}$ & $\begin{array}{c}\text { I. / I. } \\
\text { R. / N. } \\
\text { I. / I. }\end{array}$ \\
\hline
\end{tabular}

Notes: Results are for 09/1977-09/2008 for CAD, CHF, GBP, JPY, and 12/1978-09/2008 for the combined series of DEM (until 12/1998) and EUR (from 01/1999). $\alpha$ and $\beta$ are the estimates of the Fama-regression with heteroscedasticity and autocorrelation consistent standard errors, following Newey and West (1987), in parentheses. Based on equation (17) and a Sharpe ratio threshold of 0.5 , the upper $\left(\beta^{u}\right)$ and lower $\left(\beta^{l}\right)$ bound as well as the center $\left(\beta^{c}\right)$ of the inaction range for the static trading approach are calculated, first setting $\alpha=0$, second using $\alpha$ from the Fama regression. The values in square brackets are the p-values for testing whether $\beta$ is below $\beta^{u}, \beta$ equals $\beta^{c}$, and $\beta$ is above $\beta^{l}$. The last three rows summarize these findings by indicating whether the hypothesis of $\beta=\beta^{c}$ is rejected (R.) or not rejected (N.) and whether $\beta$ is inside (I.) or outside (O.) the lower bound and the upper bound when comparing the bounds calculated with $\alpha=0$ or the Fama- $\alpha$ respectively. 
Table 4: Trader Inaction Ranges for Carry-Trades

\begin{tabular}{|c|c|c|c|c|c|}
\hline & CAD & CHF & GBP & JPY & DEM-EUR \\
\hline \multicolumn{6}{|c|}{ Fama-regression } \\
\hline $\bar{\alpha}$ & $\begin{array}{c}-0.0006 \\
(0.0010)\end{array}$ & $\begin{array}{c}0.0056 \\
(0.0028)\end{array}$ & $\begin{array}{c}-0.0033 \\
(0.0019)\end{array}$ & $\begin{array}{c}0.0100 \\
(0.0027)\end{array}$ & $\begin{array}{c}0.0021 \\
(0.0020)\end{array}$ \\
\hline$\beta$ & $\begin{array}{r}-0.9858 \\
(0.4728)\end{array}$ & $\begin{array}{c}-1.2915 \\
(0.7288)\end{array}$ & $\begin{array}{c}-2.1322 \\
(1.057)\end{array}$ & $\begin{array}{c}-2.4954 \\
(0.7205)\end{array}$ & $\begin{array}{r}-1.0907 \\
(0.7979)\end{array}$ \\
\hline \multicolumn{6}{|c|}{ Bounds with $\alpha=0$} \\
\hline$\overline{\beta^{u}}$ & $\begin{array}{c}2.5773 \\
{[1.0000]}\end{array}$ & $\begin{array}{c}1.9724 \\
{[1.0000]}\end{array}$ & $\begin{array}{c}3.4478 \\
{[1.0000]}\end{array}$ & $\begin{array}{c}2.3521 \\
{[1.0000]}\end{array}$ & $\begin{array}{c}2.8463 \\
{[1.0000]}\end{array}$ \\
\hline$\beta^{c}$ & $\begin{array}{c}0.7122 \\
{[0.0004]}\end{array}$ & $\begin{array}{c}0.4256 \\
{[0.0190]}\end{array}$ & $\begin{array}{c}1.2738 \\
{[0.0014]}\end{array}$ & $\begin{array}{c}0.8646 \\
{[0.0000]}\end{array}$ & $\begin{array}{c}0.9152 \\
{[0.0124]}\end{array}$ \\
\hline$\beta^{l}$ & $\begin{array}{r}-1.1734 \\
{[0.6541]}\end{array}$ & $\begin{array}{r}-1.1581 \\
{[0.4274]}\end{array}$ & $\begin{array}{r}-0.8810 \\
{[0.1186]}\end{array}$ & $\begin{array}{c}-0.6309 \\
{[0.0050]}\end{array}$ & $\begin{array}{r}-1.0211 \\
{[0.4653]}\end{array}$ \\
\hline \multicolumn{6}{|c|}{ Bounds with Fama- $\alpha$} \\
\hline$\overline{\beta^{u}}$ & $\begin{array}{c}2.4302 \\
{[1.0000]}\end{array}$ & $\begin{array}{c}0.7582 \\
{[0.9974]}\end{array}$ & $\begin{array}{c}2.4381 \\
{[1.0000]}\end{array}$ & $\begin{array}{r}-0.1690 \\
{[0.9993]}\end{array}$ & $\begin{array}{c}2.4568 \\
{[1.0000]}\end{array}$ \\
\hline$\beta^{c}$ & $\begin{array}{c}0.5643 \\
{[0.0011]}\end{array}$ & $\begin{array}{r}-0.7943 \\
{[0.4955]}\end{array}$ & $\begin{array}{c}0.2646 \\
{[0.0239]}\end{array}$ & $\begin{array}{c}-1.6715 \\
{[0.2536]}\end{array}$ & $\begin{array}{c}0.5240 \\
{[0.0437]}\end{array}$ \\
\hline$\beta^{l}$ & $\begin{array}{r}-1.3220 \\
{[0.7612]}\end{array}$ & $\begin{array}{r}-2.4018 \\
{[0.9358]}\end{array}$ & $\begin{array}{c}-1.9061 \\
{[0.4153]}\end{array}$ & $\begin{array}{c}-3.2069 \\
{[0.8380]}\end{array}$ & $\begin{array}{r}-1.4183 \\
{[0.6592]}\end{array}$ \\
\hline \multicolumn{6}{|c|}{ Inference $\alpha=0 /$ Fama- $\alpha$} \\
\hline $\begin{array}{l}\overline{\beta^{u}} \\
\beta^{c} \\
\beta^{l}\end{array}$ & $\begin{array}{l}\text { I. / I. } \\
\text { R. / R. } \\
\text { I. / I. }\end{array}$ & $\begin{array}{l}\text { I. / I. } \\
\text { R. / N. } \\
\text { I. / I. }\end{array}$ & $\begin{array}{l}\text { I. / I. } \\
\text { R. / R. } \\
\text { I. / I. }\end{array}$ & $\begin{array}{c}\text { I. / I. } \\
\text { R. / N. } \\
\text { O. / I. }\end{array}$ & $\begin{array}{c}\text { I. / I. } \\
\text { R. / R. } \\
\text { I. / I. }\end{array}$ \\
\hline
\end{tabular}

Notes: Results are for 09/1977-09/2008 for CAD, CHF, GBP, JPY, and 12/1978-09/2008 for the combined series of DEM (until 12/1998) and EUR (from 01/1999). $\alpha$ and $\beta$ are the estimates of the Fama-regression with heteroscedasticity and autocorrelation consistent standard errors, following Newey and West (1987), in parentheses. Based on equation (19) and a Sharpe ratio threshold of 0.5 , the upper $\left(\beta^{u}\right)$ and lower $\left(\beta^{l}\right)$ bound as well as the center $\left(\beta^{c}\right)$ of the inaction range for the carry-trade are calculated, first setting $\alpha=0$, second using $\alpha$ from the Fama regression. The values in square brackets are the p-values for testing whether $\beta$ is below $\beta^{u}, \beta$ equals $\beta^{c}$, and $\beta$ is above $\beta^{l}$. The last three rows summarize these findings by indicating whether the hypothesis of $\beta=\beta^{c}$ is rejected (R.) or not rejected (N.) and whether $\beta$ is inside (I.) or outside (O.) the lower bound and the upper bound when comparing the bounds calculated with $\alpha=0$ or the Fama- $\alpha$ respectively. 
Table 5: Trader Inaction Ranges for Carry-Trades until 12/2005

\begin{tabular}{|c|c|c|c|c|c|}
\hline & $\overline{\mathrm{CAD}}$ & $\overline{\mathrm{CHF}}$ & $\overline{\mathrm{GBP}}$ & 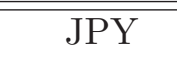 & "DEM-EUR \\
\hline \multicolumn{6}{|c|}{ Fama-regression } \\
\hline $\bar{\alpha}$ & $\begin{array}{c}-0.0013 \\
(0.0009)\end{array}$ & $\begin{array}{c}0.0054 \\
(0.0029)\end{array}$ & $\begin{array}{c}-0.0042 \\
(0.0019)\end{array}$ & $\begin{array}{c}0.0100 \\
(0.0027)\end{array}$ & $\begin{array}{c}0.0018 \\
(0.0022)\end{array}$ \\
\hline$\beta$ & $\begin{array}{c}-1.3714 \\
(0.4144)\end{array}$ & $\begin{array}{c}-1.3316 \\
(0.7338)\end{array}$ & $\begin{array}{c}-2.4778 \\
(1.0639)\end{array}$ & $\begin{array}{c}-2.5434 \\
(0.7374)\end{array}$ & $\begin{array}{c}-1.1993 \\
(0.8051)\end{array}$ \\
\hline \multicolumn{6}{|c|}{ Bounds with $\alpha=0$} \\
\hline$\beta^{u}$ & $\begin{array}{c}2.7766 \\
{[1.0000]}\end{array}$ & $\begin{array}{c}1.9294 \\
{[1.0000]}\end{array}$ & $\begin{array}{c}3.5921 \\
{[1.0000]}\end{array}$ & $\begin{array}{c}2.3921 \\
{[1.0000]}\end{array}$ & $\begin{array}{c}3.0019 \\
{[1.0000]}\end{array}$ \\
\hline$\beta^{c}$ & $\begin{array}{c}1.0891 \\
{[0.0000]}\end{array}$ & $\begin{array}{c}0.3960 \\
{[0.0191]}\end{array}$ & $\begin{array}{c}1.4850 \\
{[0.0002]}\end{array}$ & $\begin{array}{c}0.8517 \\
{[0.0000]}\end{array}$ & $\begin{array}{c}1.0947 \\
{[0.0047]}\end{array}$ \\
\hline$\beta^{l}$ & $\begin{array}{r}-0.5920 \\
{[0.0304]}\end{array}$ & $\begin{array}{r}-1.1762 \\
{[0.4162]}\end{array}$ & $\begin{array}{c}-0.5892 \\
{[0.0384]}\end{array}$ & $\begin{array}{r}-0.6975 \\
{[0.0064]}\end{array}$ & $\begin{array}{r}-0.8068 \\
{[0.3131]}\end{array}$ \\
\hline \multicolumn{6}{|c|}{ Bounds with Fama- $\alpha$} \\
\hline$\beta^{u}$ & $\begin{array}{c}2.3803 \\
{[1.0000]}\end{array}$ & $\begin{array}{c}0.8292 \\
{[0.9983]}\end{array}$ & $\begin{array}{c}2.2907 \\
{[1.0000]}\end{array}$ & $\begin{array}{c}-0.0801 \\
{[0.9995]}\end{array}$ & $\begin{array}{c}2.6938 \\
{[1.0000]}\end{array}$ \\
\hline$\beta^{c}$ & $\begin{array}{c}0.6902 \\
{[0.0000]}\end{array}$ & $\begin{array}{c}-0.7100 \\
{[0.3975]}\end{array}$ & $\begin{array}{c}0.1841 \\
{[0.0128]}\end{array}$ & $\begin{array}{c}-1.6359 \\
{[0.2193]}\end{array}$ & $\begin{array}{c}0.7857 \\
{[0.0142]}\end{array}$ \\
\hline$\beta^{l}$ & $\begin{array}{r}-0.9967 \\
{[0.1833]}\end{array}$ & $\begin{array}{r}-2.3027 \\
{[0.9067]}\end{array}$ & $\begin{array}{r}-1.9114 \\
{[0.2974]}\end{array}$ & $\begin{array}{r}-3.2270 \\
{[0.8227]}\end{array}$ & $\begin{array}{r}-1.1197 \\
{[0.4606]}\end{array}$ \\
\hline \multicolumn{6}{|c|}{ Inference $\alpha=0 /$ Fama- $\alpha$} \\
\hline $\begin{array}{l}\beta^{u} \\
\beta^{c} \\
\beta^{l}\end{array}$ & $\begin{array}{l}\text { I. / I. } \\
\text { R. / R. } \\
\text { O. / I. }\end{array}$ & $\begin{array}{c}\text { I. / I. } \\
\text { R. / N. } \\
\text { I. / I. }\end{array}$ & $\begin{array}{l}\text { I. / I. } \\
\text { R. / R. } \\
\text { O. / I. }\end{array}$ & $\begin{array}{c}\text { I. / I. } \\
\text { R. / N. } \\
\text { O. / I. }\end{array}$ & $\begin{array}{l}\text { I. / I. } \\
\text { R. / R. } \\
\text { I. / I. }\end{array}$ \\
\hline
\end{tabular}

Notes: Results are for 09/1977-12/2005 for CAD, CHF, GBP, JPY, and 12/1978-12/2005 for the combined series of DEM (until 12/1998) and EUR (from 01/1999). $\alpha$ and $\beta$ are the estimates of the Fama-regression with heteroscedasticity and autocorrelation consistent standard errors, following Newey and West (1987), in parentheses. Based on equation (19) and a Sharpe ratio threshold of 0.5 , the upper $\left(\beta^{u}\right)$ and lower $\left(\beta^{l}\right)$ bound as well as the center $\left(\beta^{c}\right)$ of the inaction range for the carry-trade are calculated, first setting $\alpha=0$, second using $\alpha$ from the Fama regression. The values in square brackets are the p-values for testing whether $\beta$ is below $\beta^{u}, \beta$ equals $\beta^{c}$, and $\beta$ is above $\beta^{l}$. The last three rows summarize these findings by indicating whether the hypothesis of $\beta=\beta^{c}$ is rejected (R.) or not rejected (N.) and whether $\beta$ is inside (I.) or outside (O.) the lower bound and the upper bound when comparing the bounds calculated with $\alpha=0$ or the Fama- $\alpha$ respectively. 
Table 6: Model Estimates and Trader Inaction Ranges for Carry-Trade Portfolios

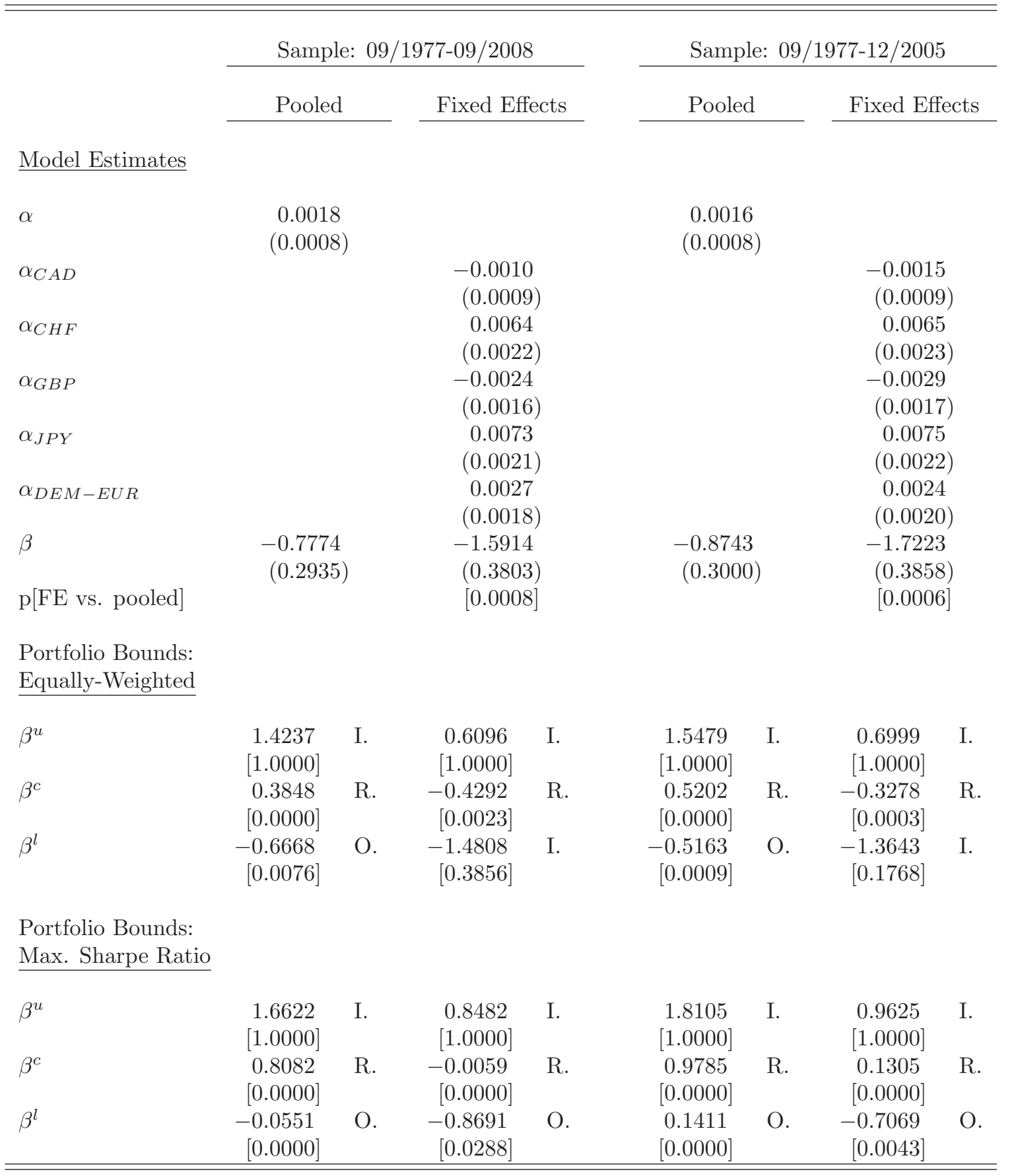

Notes: Results are for the sample periods indicated in the column headers. Estimates for the pooled regression model and the fixed effects model as described in section 5.3 are reported in the columns corresponding to their labels with heteroscedasticity and autocorrelation consistent standard errors, following Newey and West (1987), in parentheses. p[FE vs. pooled] is the p-value for the F-statistic for equal model performance. Based on equation (19) and a Sharpe ratio threshold of 0.5, the upper $\left(\beta^{u}\right)$ and lower $\left(\beta^{l}\right)$ bound as well as the center $\left(\beta^{c}\right)$ of the inaction range are calculated for the equally-weighted carry-trade portfolio and for the Sharpe ratio maximizing portfolio which are constructed as described in section 5.3. The values in square brackets are the $\mathrm{p}$-values for testing whether $\beta$ is below $\beta^{u}, \beta$ equals $\beta^{c}$, and $\beta$ is above $\beta^{l}$. The letters right to the estimated bounds summarize these findings by indicating whether the hypothesis of $\beta=\beta^{c}$ is rejected (R.) or not rejected (N.) and whether $\beta$ is inside (I.) or outside (O.) the lower bound and the upper bound. 
Figure 1: Composition of Average Excess Returns $(\overline{E R})$

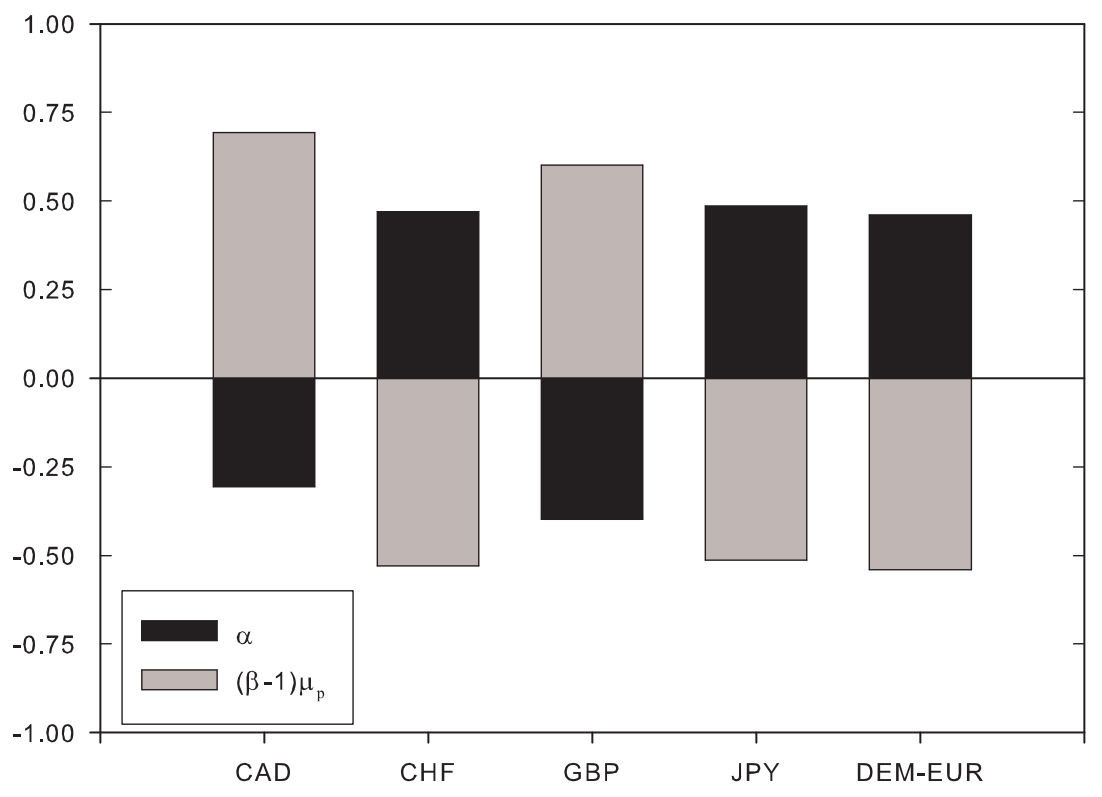

\begin{tabular}{|c|c|c|c|c|c|}
\hline & CAD & $\mathrm{CHF}$ & GBP & JPY & DEM-EUR \\
\hline \multicolumn{6}{|c|}{$\overline{E R}$-components: absolute } \\
\hline$\alpha$ & -0.0006 & 0.0056 & -0.0033 & 0.0100 & 0.0021 \\
\hline$(\beta-1) \mu_{p}$ & 0.0013 & -0.0063 & 0.0049 & -0.0106 & -0.0025 \\
\hline \multicolumn{6}{|c|}{$\overline{E R}$-components: relative } \\
\hline$\overline{[\%] \alpha}$ & $-30.67 \%$ & $47.01 \%$ & $-39.85 \%$ & $48.68 \%$ & $45.99 \%$ \\
\hline$[\%](\beta-1) \mu_{p}$ & $69.33 \%$ & $-52.99 \%$ & $60.15 \%$ & $-51.32 \%$ & $-54.01 \%$ \\
\hline \multicolumn{6}{|c|}{ Testing $\overline{(\beta-1) p_{t}^{1}}=0$} \\
\hline t-stat & 8.6268 & -17.8661 & 14.8780 & -25.4508 & -8.8428 \\
\hline
\end{tabular}

Notes: This Figure summarizes the composition of average excess returns $\overline{E R}=\alpha+(\beta-1) \mu_{p}$ as in (3). Results are for 09/1977-09/2008 for CAD, CHF, GBP, JPY, and 12/1978-09/2008 for the combined series of DEM (until 12/1998) and EUR (from 01/1999). The plot shows a stacked column diagram that visualizes the composition of average excess returns, $\overline{E R}$, based on the values reported in the tabular below the graph. The t-statistics in the last row are for testing the null hypothesis that the mean of the series of $(\beta-1) p_{t}^{1}$ is equal to zero. 
Figure 2: Sharpe Ratio Thresholds and Economic Significance

Sample: 09/1977-09/2008

Static Trading Approach

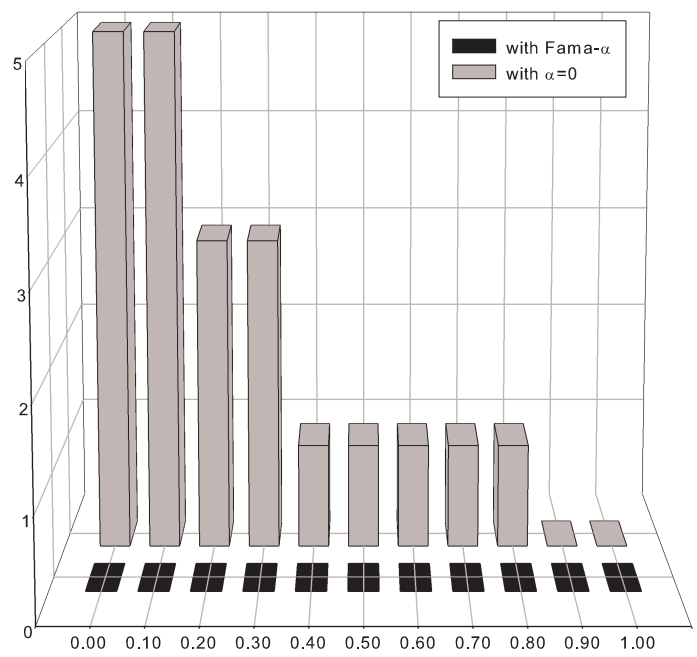

Carry-Trade

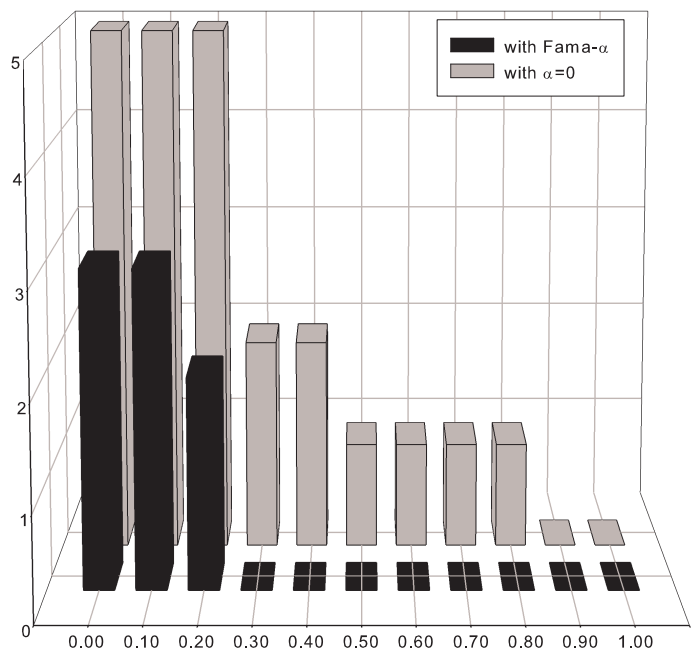

Static Trading Approach

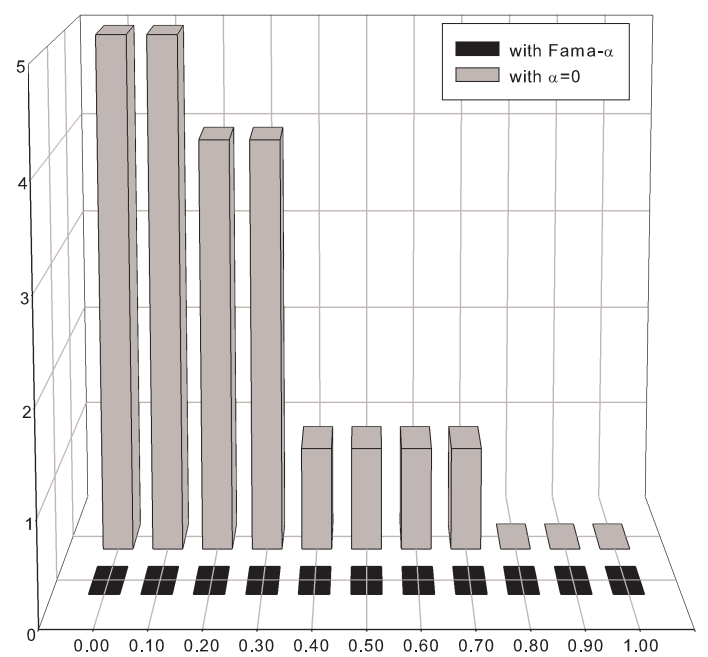

Carry-Trade

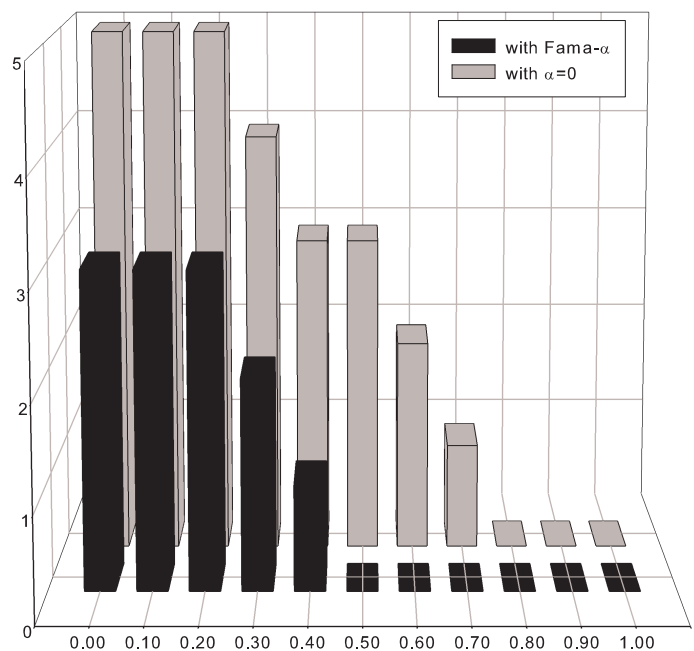

Notes: The columns plot the number of currencies for which a given Sharpe ratio threshold (x-axis) is outperformed significantly as judged by trader inaction ranges calculated with $\alpha=0$ (columns in gray) and the Fama- $\alpha$ (black) respectively. Overall, five currencies are included: CAD, CHF, GBP, JPY, and the merged series of DEM and EUR. Inaction ranges are calculated for the Static Trading Approach as described in section 4.1 (on the left) and the carry-trade as described in section 4.2 (on the right). The respective data samples are as indicated in the headers of the plots; for the DEM-EUR data is available only from $12 / 1978$. 
Figure 3: Sharpe Ratio Thresholds and Economic Significance: Carry-Trade Portfolios

Sample: 09/1977-09/2008

Equally-Weighted Portfolio

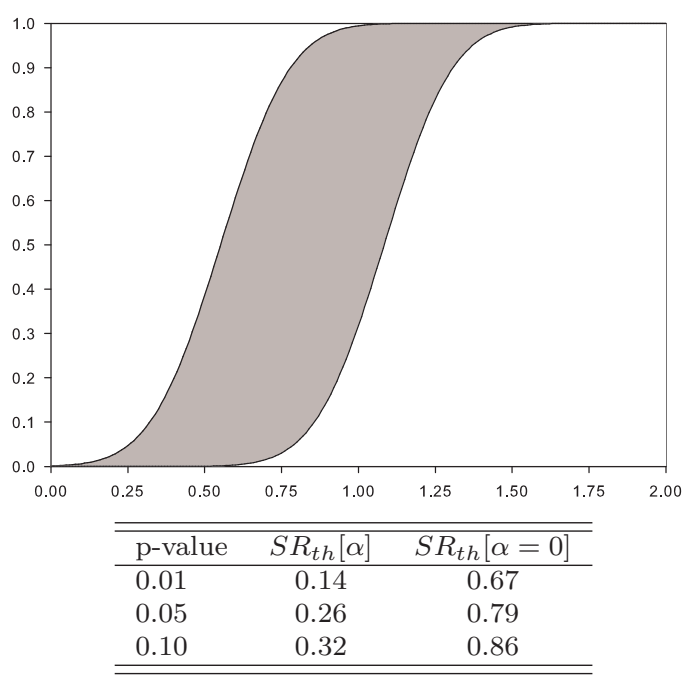

Sample: 09/1977-12/2005
Optimal Portfolio

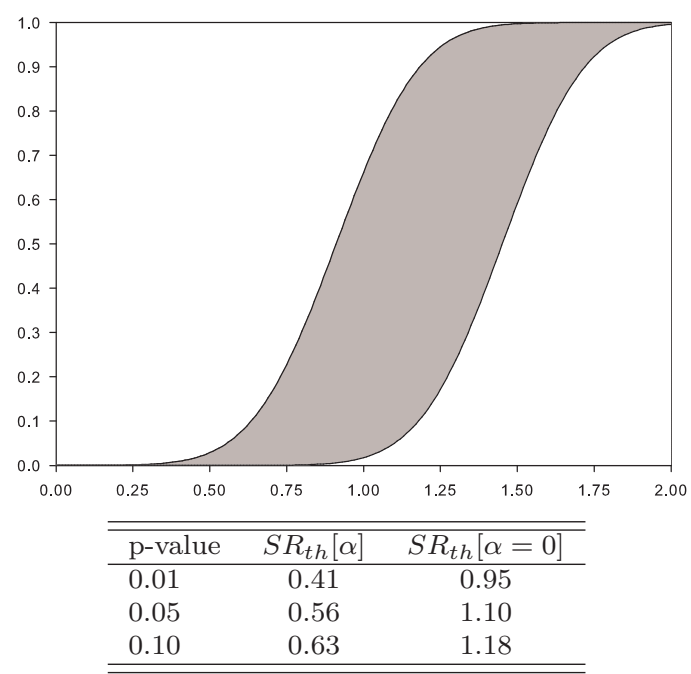

Equally-Weighted Portfolio

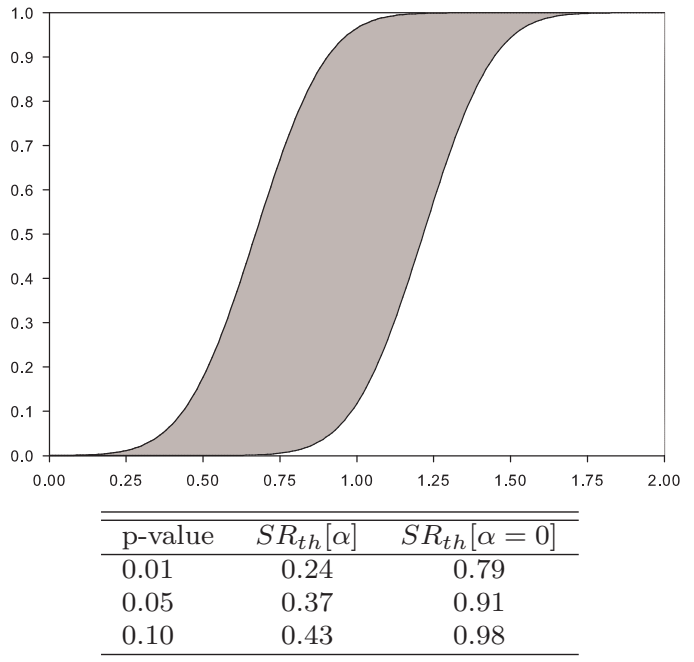

Optimal Portfolio

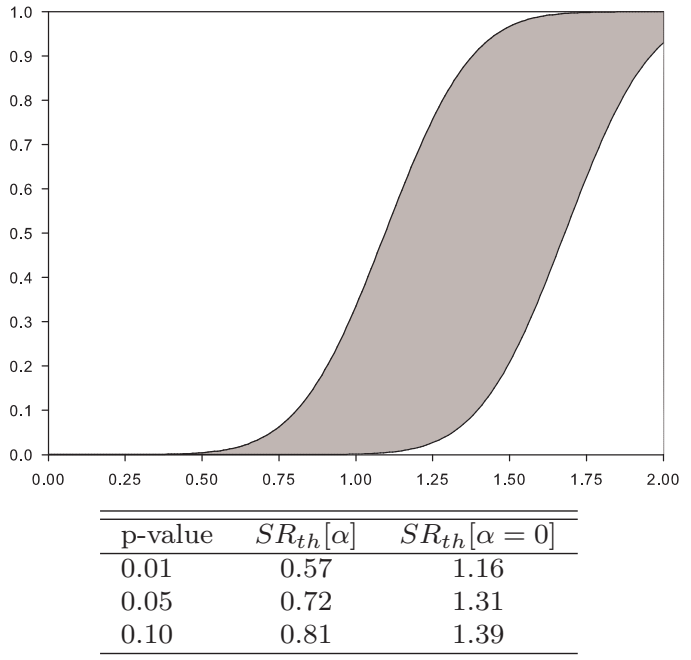

Notes: Graphs on the left are for the equally-weighted carry-trade portfolio, on the right for the optimal portfolio maximizing the Sharpe ratio. The graphs plot Sharpe ratio thresholds against the p-values at which they are outperformed significantly. With Sharpe ratio thresholds along the the x-axis and corresponding p-values along the y-axis, the upper line represents p-values when accounting for $\alpha$, the lower line represents p-values when presuming $\alpha=0$. The tables below the graphs list the Sharpe ratio thresholds which are significantly outperformed at p-values of $0.01,0.05$, and 0.1 . The respective data samples are as indicated in the headers of the plots; for the DEM-EUR data is available only from $12 / 1978$. 
Figure 4: Trader Inaction Ranges for the Carry-Trade

Bounds with $\alpha=0$

CAD

$\mathrm{CHF}$
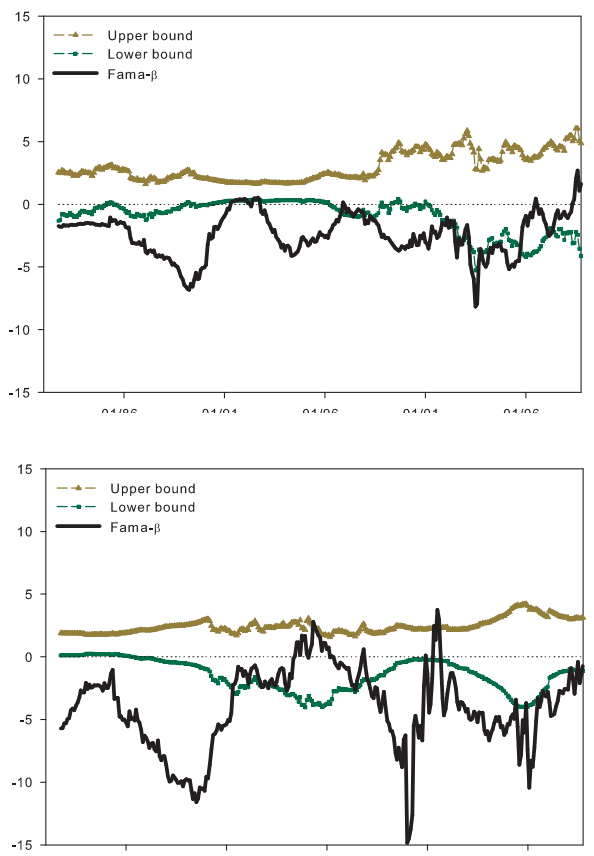

GBP

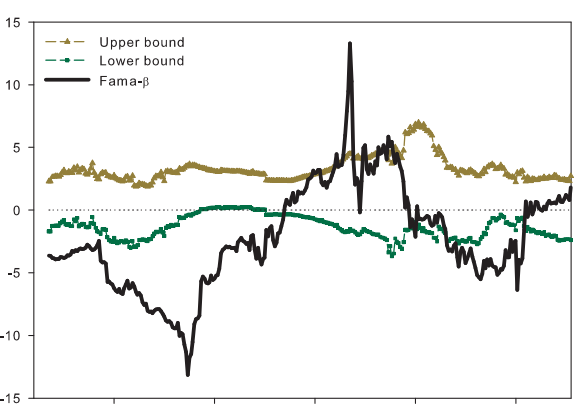

JPY

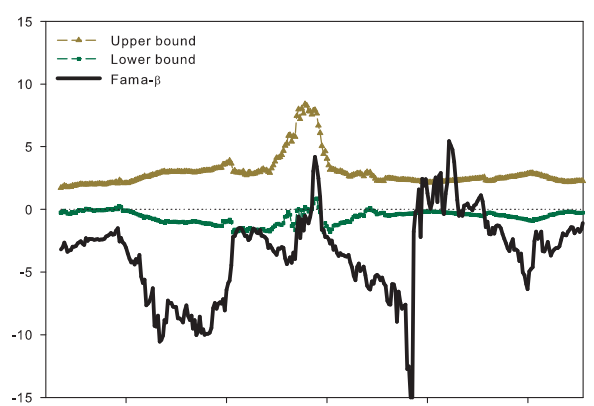

DEM-

EUR

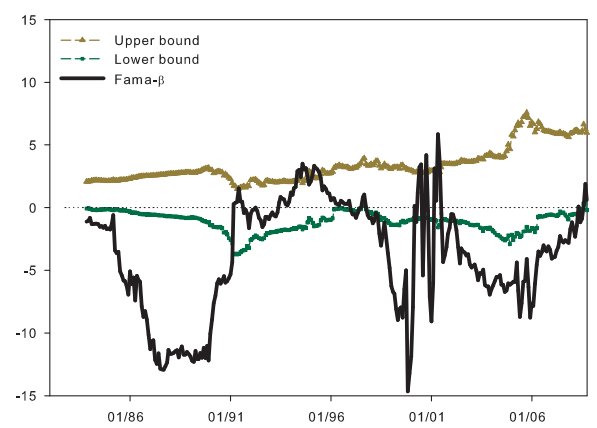

Bounds with Fama- $\alpha$
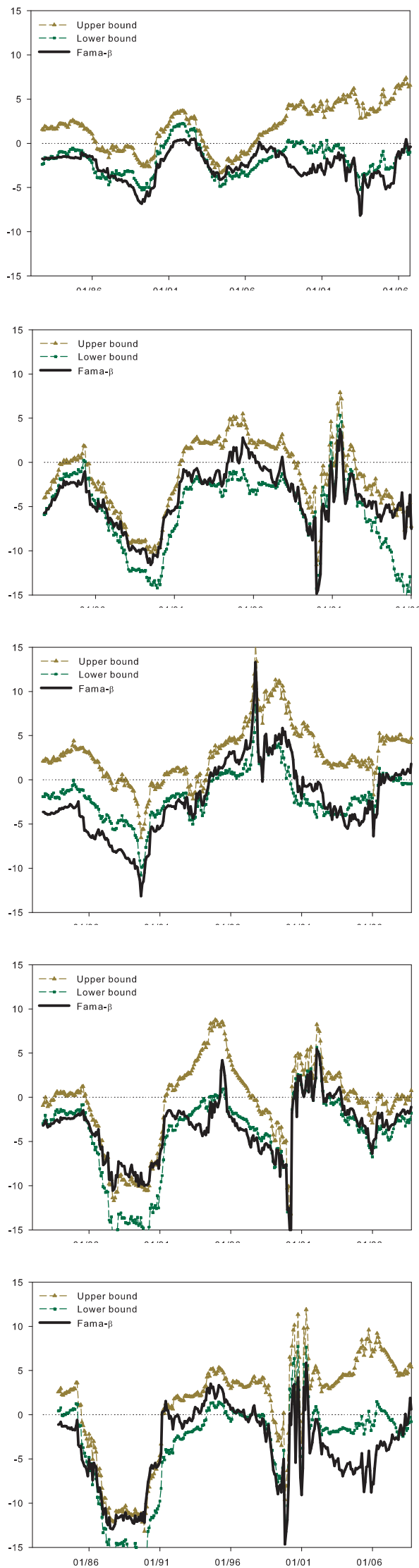

Notes: The graphs show the 60 -month rolling Fama- $\beta$ estimates for the exchange rates USD against the indicated foreign currency and the corresponding trader inaction ranges for the carry-trade. The inaction range bounds are calculated with $\alpha=0$ (left) and the Fama- $\alpha$ (right) respectively, see equation (19). The underlying Sharpe ratio threshold is 0.5. 
Figure 5: Trader Inaction Ranges for Carry-Trade Portfolios

Equally-Weighted Carry-Trade Portfolios

Fixed Effects, with $\alpha=0$

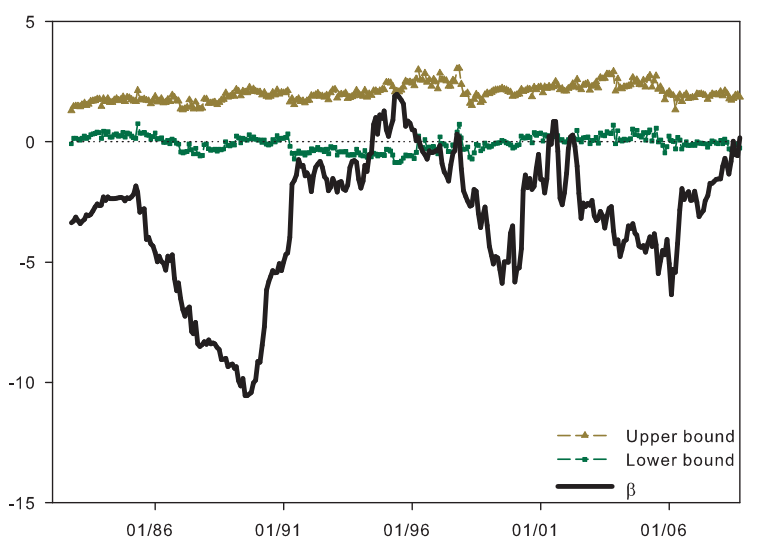

Fixed Effects, with Fama- $\alpha$

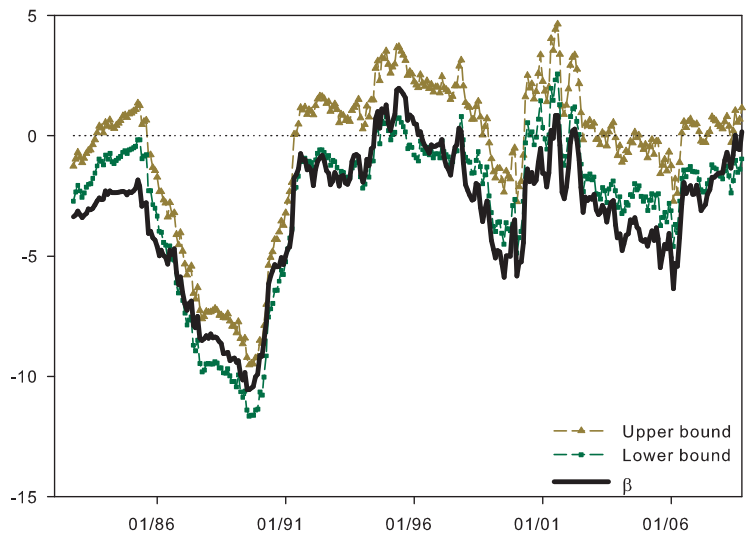

Optimal Carry-Trade Portfolios

Fixed Effects, with $\alpha=0$

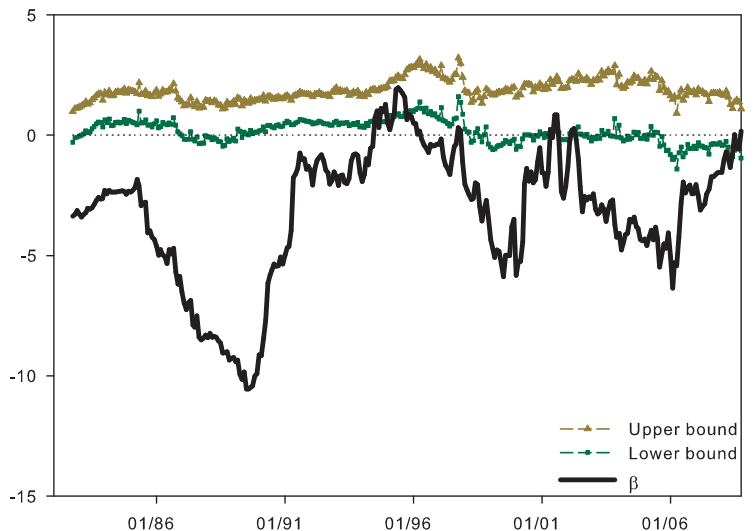

Fixed Effects, with Fama- $\alpha$

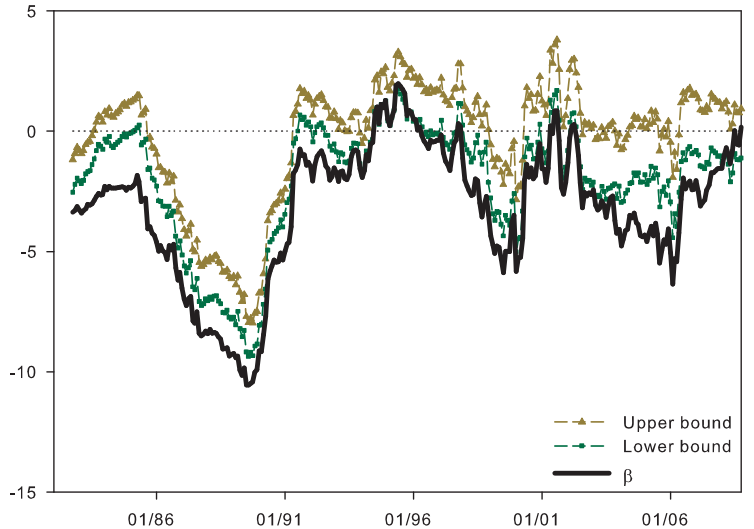

Notes: The graphs show the 60 -month rolling Fama- $\beta$ estimates of the fixed effects model for the equally-weighted and the Sharpe ratio maximizing carry-trade portfolios and their corresponding trader inaction ranges. The inaction range bounds are calculated with $\alpha=0$ (left) and the Fama- $\alpha$ (right) respectively, see equation (19). The underlying Sharpe ratio threshold is 0.5. 
Appendix (additional material, not necessarily to be published)

\section{Appendix A. Unconditional (Country) Risk-Premium}

There might be reasons for the unconditional expectation of $\overline{E R}$ to be non-zero, in particular, if the currencies considered are related to countries with different levels of risk. For instance, one country may be considered as a safe heaven as compared to the other, or one country is experiencing a transition. The framework outlined in section 4.1 does also allow to account for a corresponding unconditional country risk-premium. Let $\gamma$ denote the unconditional expectation of the country risk-premium (which might either be positive or negative), then the average excess return is given by

$$
\overline{E R}=\alpha+(\beta-1) \mu_{p}=\gamma
$$

Analogously to section 4.1, we rearrange this expression in terms of the Fama-regression slope coefficient

$$
\beta=1-\frac{\alpha-\gamma}{\mu_{p}}
$$

and impose this restriction on the regression 1. The dynamics of excess returns are then given by

$$
E R_{t+1}=\alpha-(\alpha-\gamma) \frac{p_{t}^{1}}{\mu_{p}}+\varepsilon_{t+1}
$$

which can again be empirically tested by estimating

$$
E R_{t+1}=\alpha_{1}+\alpha_{2}^{\gamma} \frac{p_{t}^{1}}{\mu_{p}}+\varepsilon_{t+1}
$$

If $\alpha_{2}^{\gamma}$ is significantly different from zero this would again provide evidence for a time-varying risk component as motivated in this paper. However, in the presence of a country risk-premium, one does not expect to find that $\alpha_{1}=-\alpha_{2}^{\gamma}$. In fact, if one proceeds as described in section 4.1 and in Test 2 , see (8), that $\alpha_{1} \neq-\alpha_{2}$, this is an indication for an unconsidered country risk-premium. Note that the procedure just described of course also nests a constant risk-premium as discussed in the traditional literature when testing the restriction $\beta=1$ but expecting $\alpha \neq 0$. In our framework this would correspond to $\gamma=\alpha$ leading to

$$
\Delta s_{t+1}=\alpha+p_{t}^{1}+\varepsilon_{t+1}
$$

\section{Appendix B. Sharpe Ratios and Trader Inaction Ranges}

This appendix summarizes the properties of Sharpe ratios and trader inaction ranges for the static trading approach. Section B.1. reports technical details when $\alpha$ is disregarded, i.e. presumed to zero, section B.2. for calculations based on the Fama- $\alpha$. We abstain from presenting analogous derivations for the carry-trade approach, since the details are lengthy but straightforward along the arguments for the static trading approach.

\section{B.1. Sharpe Ratio and Inaction Range Bounds when $\alpha=0$}




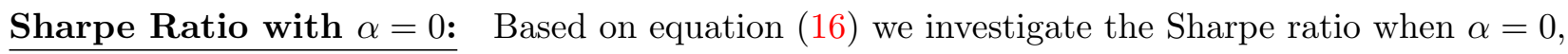

$$
S R=\frac{(\beta-1) \bar{p}}{\sqrt{(\beta-1)^{2} \sigma_{p}^{2}+\sigma_{\varepsilon}^{2}}} .
$$

The first derivative of the Sharpe ratio with respect to $\beta$ is given by

$$
\frac{\partial S R}{\partial \beta}=\frac{\mu_{p} \sigma_{\varepsilon}^{2}}{\left[\sigma_{\varepsilon}^{2}+(\beta-1)^{2} \sigma_{p}^{2}\right]^{3 / 2}},
$$

i.e. depending on the sign of $\mu_{p}$, the Sharpe ratio increases $\left(\mu_{p}>0\right)$ or decreases $\left(\mu_{p}<0\right)$ monotonically.The second derivative,

$$
\frac{\partial^{2} S R}{\partial \beta^{2}}=-\frac{3(\beta-1) \mu_{p} \sigma_{\varepsilon}^{2} \sigma_{p}^{2}}{\left[\sigma_{\varepsilon}^{2}+(\beta-1)^{2} \sigma_{p}^{2}\right]^{5 / 2}}
$$

shows that, if $\mu_{p}>0$, the Sharpe ratio function is concave $\left(\frac{\partial^{2} S R}{\partial \beta^{2}}<0\right)$ for $\beta>1$, while it is convex $\left(\frac{\partial^{2} S R}{\partial \beta^{2}}>0\right)$ for $\beta<1$. The reverse is true if $\mu_{p}<0$.Calculating the limits of the Sharpe ratio function with $\beta$ going to plus and minus infinity reveals that the Sharpe ratio is bounded:

$$
\lim _{\beta \rightarrow \infty} S R=\frac{\mu_{p} \sqrt{\sigma_{p}^{2}}}{\sigma_{p}^{2}} \quad \text { and } \quad \lim _{\beta \rightarrow-\infty} S R=-\frac{\mu_{p} \sqrt{\sigma_{p}^{2}}}{\sigma_{p}^{2}} .
$$

Inaction Range Bounds with $\alpha=0$ : Based on equation (15) we investigate the inaction range for UIP deviations when setting $\alpha=0$,

$$
\beta\left[S R_{t h}, \alpha=0\right]=\frac{ \pm S R_{t h} \sigma_{\varepsilon}}{\sqrt{\left(\mu_{p}^{2}-S R_{t h}^{2} \sigma_{p}^{2}\right)}}+1 .
$$

To investigate the shape of the inaction range bounded by a upper $\beta, \beta^{u}$ and a lower $\beta$, $\beta^{l}$, we look at the derivatives with respect to the Sharpe ratio threshold, $S R_{t h}$,

$$
\begin{aligned}
& \text { upper bound: } \quad \frac{\partial \beta^{u}}{\partial S R_{t h}}=\frac{\mu_{p}^{2} \sigma_{\varepsilon}}{\left[\mu_{p}^{2}-\sigma_{p}^{2} S R_{t h}^{2}\right]^{3 / 2}}>0 \quad \text { and } \quad \frac{\partial^{2} \beta^{u}}{\partial S R_{t h}^{2}}=\frac{3 \mu_{p}^{2} \sigma_{\varepsilon} \sigma_{p}^{2} S R_{t h}}{\left[\mu_{p}^{2}-\sigma_{p}^{2} S R_{t h}^{2}\right]^{5 / 2}}>0, \\
& \text { lower bound: } \quad \frac{\partial \beta^{l}}{\partial S R_{t h}}=-\frac{\mu_{p}^{2} \sigma_{\varepsilon}}{\left[\mu_{p}^{2}-\sigma_{p}^{2} S R_{t h}^{2}\right]^{3 / 2}}<0 \quad \text { and } \quad \frac{\partial^{2} \beta^{l}}{\partial S R_{t h}^{2}}=-\frac{3 \mu_{p}^{2} \sigma_{\varepsilon} \sigma_{p}^{2} S R_{t h}}{\left[\mu_{p}^{2}-\sigma_{p}^{2} S R_{t h}^{2}\right]^{5 / 2}}<0 .
\end{aligned}
$$

Thus, the upper bound is an increasing convex function of the Sharpe ratio threshold, while the lower bound is decreasing and concave.

\section{B.2. Sharpe Ratio and Inaction Range Bounds when using the Fama- $\alpha$}

Sharpe Ratio with Fama- $\alpha$ : In order to investigate the change in the Sharpe ratio when incorporating the Fama- $\alpha$ instead of setting $\alpha=0$, we look at the partial derivatives:

$$
\begin{aligned}
& \frac{\partial S R}{\partial \alpha}=\frac{1}{\sqrt{\sigma_{\varepsilon}^{2}+(\beta-1)^{2} \sigma_{p}^{2}}}, \\
& \frac{\partial^{2} S R}{\partial \alpha^{2}}=0 .
\end{aligned}
$$


Hence, depending on the sign of $\alpha$, the Sharpe ratio changes inversely proportional to the standard deviation.Looking at the partial derivatives of the Sharpe ratio with respect to $\beta$,

$$
\begin{aligned}
& \frac{\partial S R}{\partial \beta}=\frac{\mu_{p} \sigma_{\varepsilon}^{2}-\alpha(\beta-1) \sigma_{p}^{2}}{\left[\sigma_{\varepsilon}^{2}+(\beta-1)^{2} \sigma_{p}^{2}\right]^{3 / 2}}, \\
& \frac{\partial^{2} S R}{\partial \beta^{2}}=-\frac{3(\beta-1) \mu_{p} \sigma_{\varepsilon}^{2} \sigma_{p}^{2}+\alpha \sigma_{p}^{2}\left[\sigma_{\varepsilon}^{2}-2(\beta-1)^{2} \sigma_{p}^{2}\right]}{\left[\sigma_{\varepsilon}^{2}+(\beta-1)^{2} \sigma_{p}^{2}\right]^{5 / 2}}
\end{aligned}
$$

reveals that the function is non-monotonic. While the Sharpe ratio is still bounded with the same limits as given above, the global optimum, i.e. $\partial S R / \partial \beta=0$, is not reached with $\beta$ going to plus or minus infinity but when $\beta=\left(\mu_{p} \sigma_{\varepsilon}\right) /\left(\alpha \sigma_{p}\right)+1$.

Inaction Range Bounds with Fama- $\alpha$ : To investigate the impact of including $\alpha$ in the assessment of economic significance, we consider the partial derivatives of the inaction range bounds with respect to $\alpha$ :

upper bound:

$$
\frac{\partial \beta^{u}}{\partial \alpha}=\frac{-\mu_{p}+\frac{\alpha \sigma_{p}^{2} S R_{t h}}{\sqrt{\alpha^{2} \sigma_{p}^{2}+\sigma_{\varepsilon}^{2}\left(\mu_{p}^{2}-\sigma_{p}^{2} S R_{t h}^{2}\right)}}}{\mu_{p}^{2}-\sigma_{p}^{2} S R_{t h}^{2}} \quad \text { and } \quad \frac{\partial^{2} \beta^{u}}{\partial \alpha^{2}}=\frac{\sigma_{\varepsilon}^{2} \sigma_{p}^{2} S R_{t h}}{\left[\sigma_{\varepsilon}^{2}\left(\mu_{p}^{2}-\sigma_{p}^{2} S R_{t h}^{2}\right)+\alpha^{2} \sigma_{p}^{2}\right]^{3 / 2}}>0,
$$

lower bound:

$$
\frac{\partial \beta^{l}}{\partial \alpha}=\frac{-\mu_{p}-\frac{\alpha \sigma_{p}^{2} S R_{t h}}{\sqrt{\alpha^{2} \sigma_{p}^{2}+\sigma_{\varepsilon}^{2}\left(\mu_{p}^{2}-\sigma_{p}^{2} S R_{t h}^{2}\right)}}}{\mu_{p}^{2}-\sigma_{p}^{2} S R_{t h}^{2}} \quad \text { and } \quad \frac{\partial^{2} \beta^{l}}{\partial \alpha^{2}}=-\frac{\sigma_{\varepsilon}^{2} \sigma_{p}^{2} S R_{t h}}{\left[\sigma_{\varepsilon}^{2}\left(\mu_{p}^{2}-\sigma_{p}^{2} S R_{t h}^{2}\right)+\alpha^{2} \sigma_{p}^{2}\right]^{3 / 2}}<0
$$

indicating that a non-zero $\alpha$ affects the level as well as the shape of the inaction range.

\section{Appendix C. Testing Inaction Range Bounds}

To test whether $\beta$ significantly overshoots the upper bound or undershoots the lower bound, we use the nonlinear analog to the $F$ statistic; see e.g. Greene (2003) p.175ff. The general specification

$$
F[J, n-K]=\frac{\left[S\left(\mathbf{b}_{*}\right)-S(\mathbf{b})\right] / J}{S(\mathbf{b}) /(n-K)}
$$

where $\mathbf{b}_{*}$ denotes the estimates obtained when the hypothesis is imposed and $\mathbf{b}$ denotes the unrestricted estimates. $J$ is the number of restrictions, $n$ the number of observations, $K$ the number of parameters. $S(\cdot)$ denotes sum of squared residuals of the estimation with $\mathbf{b}_{*}$ and $\mathbf{b}$ respectively. The test statistic is (approximately) $F$-distributed with $[J, n-K]$ degrees of freedom.

One could also use a Wald test which might be simpler to compute. However, as also for the linear case, the Wald statistic is not invariant to how hypotheses are formulated, potentially leading to different answers depending on the specification of the hypothesis. Furthermore, Greene (2003) p. 176 states that "the small-sample behavior of $W$ can be erratic, and the more conservative $F$ statistic may be preferable if the sample is not large". 
To judge whether $\beta$ overshoots the upper bound $\beta^{u}$, we want to obtain the probability that $\beta$ is within the inaction range, i.e. whether $\beta<\beta^{u}$. Since our $F$-Test has one numerator degree of freedom, the square-root of the $F$-statistic corresponds to the absolute value of the $t$-statistic for the one-sided test. Taking the sign of the estimate into account, the probability that $\beta$ is below $\beta^{u}$ is therefore given by the reverse cumulative t-distribution for $\operatorname{sgn}\left[\beta-\beta^{u}\right] \sqrt{F_{[J, n-k]}}$ with $(n-k)$ degrees of freedom. If this probability is below our confidence level threshold, we reject the hypothesis and say that $\beta$ overshoots the upper bound. For the lower bound we proceed analogously. 